\title{
Solving Fuzzy Multiproduct Aggregate Production Planning Problems Based on Extension Principle
}

\author{
Shih-Pin Chen and Wen-Lung Huang \\ Department of Business Administration, National Chung Cheng University, Minhsiung, Chiayi 621, Taiwan \\ Correspondence should be addressed to Shih-Pin Chen; chensp@ccu.edu.tw
}

Received 1 February 2014; Accepted 17 June 2014; Published 3 August 2014

Academic Editor: Shey-Huei Sheu

Copyright (C) 2014 S.-P. Chen and W.-L. Huang. This is an open access article distributed under the Creative Commons Attribution License, which permits unrestricted use, distribution, and reproduction in any medium, provided the original work is properly cited.

\begin{abstract}
Aggregate production planning (APP) plays a critical role in supply chain management (SCM). This paper investigates multiproduct, multiperiod APP problems with several distinct types of fuzzy uncertainties. In contrast to the existing studies, the modelling in this work conserves the fuzziness such that the obtained APP is more effective. Based on Zadeh's extension principle, the results obtained are fuzzy solutions described by membership functions, in contrast to results from previous studies. A pair of two-level parametric mathematical programs is formulated to calculate the lower and upper bounds of the optimum fuzzy performance measure. The membership function of the fuzzy total cost is constructed by enumerating various possibility levels. A case studied in previous research is investigated to demonstrate the validity of the proposed model and solution procedure. Because the optimal objective value and associated decision variables are expressed using fuzzy numbers rather than crisp values, the proposed approach is able to represent APP systems more accurately, and therefore, the results obtained can provide decision makers with more effective and informative APPs and more chance to achieve the optimal disaggregate plan.
\end{abstract}

\section{Introduction}

Current trends in the highly competitive and dynamic business environment are driving companies across the globe to move towards aggregate production planning (APP) with the intent of finding optimum balance among capacity, forecasted demand, and fluctuating customer orders over the midterm, often from 3 to 18 months ahead. An ample body of research has indicated that this optimum is achieved through management that includes the primary objective of adjusting the controllable factors (e.g., regular and overtime production rates, inventory levels, and labour levels) under a given set of production resources and constraints during each phase of the planning horizon [1-5].

The APP problem has been extensively investigated over the last few decades, and a significant amount of effort has been expended in the development of new decision models. By reviewing previous studies, Saad [6] examined the conventional decision models and classified them into the following six categories: (1) the linear decision rule (LDR) [7], (2) the transportation method [8], (3) linear programming (LP) [9], (4) the management coefficient approach [10],
(5) simulation approaches [11], and (6) the search decision rule [12]. In the following decades, studies were focused on developing a variety of optimisation models [1], and more recent studies include those of Baykasoglu [13], Jain and Palekar [12], Gomes da Silva et al. [14], Leung et al. [15], and Leung and Chan [16].

The development of the above-mentioned models took place under crisp environments, and the resulting models belong to deterministic or stochastic optimisation methods $[1,17,18]$. However, Mula et al. [18] also noted that the APP problem is associated with elements that raise the uncertainty of the nonstochastic elements (e.g., customer demand, lead times, production fluctuation, and their associated costs). Many attempts have been made to categorise problems of this type. In practical applications, in place of probability distributions, such linguistic terms as "approximately 1.6 meters," "often," "moderate," and "rare" may be embedded in APP, and this information is obtained subjectively from management $[19,20]$.

Fuzzy set theory was first introduced by Zadeh [21] to handle uncertainties in the nonstochastic sense. Because the 
APP problem in crisp environments can be modelled as an LP model, several fuzzy optimisation methods for solving fuzzy APP problems have been developed based on the fuzzy LP (FLP) [22-28]. For example, Lee [29] investigated singleproduct APP problems with fuzzy objectives, workforce levels, and demands. Other studies include the works by Lai and Hwang [30], Dai et al. [31], Wang and Fang [28, 32], and Wang and Liang $[19,33]$.

In practice, most companies produce multiple products, and thus, many fuzzy parameters of different types exist. Therefore, practical multiproduct APP problems are more complicated than the single-product APP often presented in modelling and solution procedures, and these more complicated problems deserve further investigation. For multiproduct APP problems, Tang et al. [34] developed a model characterised by fuzzy resource right-hand-side constraints (i.e., demands and capacities). Soon after, Wang and Fang [32] discussed a multiobjective APP problem in which the objective function coefficients (i.e., production prices and subcontracting costs) and resource right-handside constraints (i.e., manpower levels, production capacities, and market demands) were characterised by fuzziness values that were in turn included in the model as trapezoidal fuzzy numbers. Wang and Liang [33] and Liang [35] applied a possibilistic linear programming (PLP) [30] approach to solving multiproduct APP problems associated with multiple imprecise objectives and cost coefficients, and the demands were described by triangular possibility distributions in uncertain environments. Aliev et al. [36] proposed an approach based on the genetic algorithm (GA) for the fuzzy multiproduct aggregate production-distribution planning (APDP) problem in supply chain management (SCM).

Tang et al. [34] emphasised that any single optimal solution should not be taken as a guarantee of reaching a viable disaggregate plan. Furthermore, Chen and Huang [37] reviewed the models and solution methods for APP problems and noted that most of the existing methods may fail to maintain the fuzziness of the input information, which can be used to represent the fuzzy APP more accurately. It thus becomes apparent that the performance measures are characterised by fuzziness because multiple parameters in an APP model are also fuzzy. Furthermore, conserving the fuzziness of the input information is possible if the model offers the opportunity to derive descriptive membership functions of certain performance measures. Better representation of the fuzziness will thus facilitate the user in attaining a performance measure that is a more logical and more accurate representation of the fuzzy APP. The abovementioned approaches offer crisp solutions that are prone to either under- or overestimates, thus leading users to make faulty decisions.

To overcome this shortcoming, Chen and Huang [37] proposed a solution procedure that is able to find the fuzzy objective value of the fuzzy APP model. However, they only investigated the single-product APP problem with two sets of fuzzy parameters, the maximum workforce available and the forecasted demand. In fact, their model is a FLP model with crisp objective coefficients, crisp left-hand-side constraints, and fuzzy right-hand sides with two sets of constraints. As stated previously, multiproduct APP problems are more complicated than their single-product counterparts. This paper investigates the multiproduct, multiperiod APP problem with several fuzzy parameters of different types. More importantly, the solutions obtained by solving the proposed model are also fuzzy and thus conserve fuzziness in the general nature, indicating that the proposed model can provide an effective APP and a feasible disaggregate plan can be obtained.

This paper proposes a cost-based multiproduct/ multiperiod APP model with several sets of fuzzy parameters, including the unit production costs excluding labour costs, overtime labour costs, labour costs, inventory carrying costs, costs to hire one worker, costs to lay off one worker, unit backorder costs, conversion factors in hours of labour, forecasted demands, and maximum workforce. A solution procedure that is able to calculate the fuzzy objective value of the fuzzy APP model is also developed. The main concept is based on the application of $\alpha$-cuts and Zadeh's extension principle [38, 39 ] to transform the fuzzy APP model into a family of crisp APP models. A pair of two-level mathematical programs $[40,41]$ is formulated to calculate the lower and upper bounds of the $\alpha$-cut of the fuzzy minimum total cost. Consequently, the membership function of the fuzzy minimum total cost is derived analytically or numerically by enumerating different values of $\alpha$. Because the proposed approach is based on Zadeh's extension principle, it is significantly different from those of several related studies (e.g., $[30,31])$, which may fail to compute the sets of possible values of the fuzzy minimum total cost.

This paper is organised as follows. First, an extensive fuzzy multiproduct APP model with multiple fuzzy parameters is constructed in Section 2 based on the work of Lai and Hwang [30]. Based on Zadeh's extension principle, Section 3 presents a pair of mathematical programs for calculating the $\alpha$-cuts of the fuzzy minimum total cost. Next, a modified two-product six-period APP example referenced by Lai and Hwang [30] is successfully investigated in Section 4 to demonstrate the validity of the proposed approach and is compared with one of the classical methods, that is, Chanas' approach [30], in Section 5. Finally, conclusions are presented in Section 6.

\section{Modelling the Fuzzy Multiproduct APP}

This paper constructs the multiproduct APP model with many fuzzy parameters of different types based on the LP formulation. In this section, the crisp LP and general fuzzy LP models are briefly introduced.

2.1. Fuzzy Linear Programming. The LP method has been demonstrated as one of the most frequently used operational research/management science (OR/MS) techniques for practical problems [42]. The LP method focuses on the effective and efficient allocation of limited resources to interrelated activities with the objective of achieving a prespecified goal, such as profit maximisation [43]. The general maximisation 
LP model can be described in the canonical form using matrix notation [44]:

$$
\begin{array}{ll}
\max . & \mathbf{c}^{t} \mathbf{x} \\
\text { s.t. } & \mathbf{A x} \leq \mathbf{b}, \\
& \mathbf{x} \geq \mathbf{0},
\end{array}
$$

where $c^{t}$ denotes the transpose of the vector of the profit coefficients of the objective function, $\mathbf{A}$ is the constraint matrix, $\mathbf{x}$ is the vector of decision variables (or activity levels), and $\mathbf{b}$ is the vector of total resources available. Note that in this model, all coefficients of $\mathbf{A}, \mathbf{b}$, and $\mathbf{c}$ are crisp numbers and each constraint must be strictly satisfied. In practical situations, the input data for this model are typically imprecise due to incomplete information [30]; in addition, the vagueness in these input data may not be probabilistic. As Rommelfanger [27] noted, "LP requires much well-defined and precise data which involves high information costs," and its assumptions [42] are often too strict to limit the LP applications.

To quantitatively address the imprecise information in the decision-making process, Zadeh [21] introduced the concept of fuzzy set theory. Since then, additional research has developed specific FLP models and proposed the associated solution methods. In fact, so many different types of FLP models exist that Lai and Hwang [30] provided a detailed and systematic classification. In general, the basic types of FLP can be grouped into the following six categories: (1) fuzzy objective and precise constraints, (2) precise objective and fuzzy constraint matrix, (3) precise objective and fuzzy total resources available, (4) fuzzy objective and fuzzy constraint matrix, (5) fuzzy objective and fuzzy total resources available, and (6) fuzzy objective and fuzzy constraints, including the constraint matrix and total resources available [26]. In other words, the possible combinations of the fuzziness of $\mathbf{c}, \mathbf{A}$, and b are (1) fuzzy c only, (2) fuzzy A only, (3) fuzzy b only, (4) fuzzy $\mathbf{c}$ and $\mathbf{A}$, (5) fuzzy $\mathbf{c}$ and $\mathbf{b}$, and (6) fuzzy $\mathbf{c}, \mathbf{A}$, and $\mathbf{b}$. Numerous studies have been devoted to developing different types of solution methods for these six types of FLP models.

Instead of describing all of the types of FLP models, the general FLP model with fuzzy $\mathbf{c}, \mathbf{A}$, and $\mathbf{b}$ is exemplified as follows:

$$
\begin{array}{ll}
\max . & \widetilde{\mathbf{c}}^{t} \mathbf{x} \\
\text { s.t. } & \widetilde{\mathbf{A}} \mathbf{x} \leq \widetilde{\mathbf{b}}, \\
& \mathbf{x} \geq \mathbf{0} .
\end{array}
$$

Clearly, the assumption of certainty for the crisp LP is relaxed to fit real-world situations. Moreover, the operations of addition and multiplication are operations of fuzzy arithmetic, and " $\leq$ " denotes the ordering of fuzzy numbers [26]. Note that the proposed model in the next subsection is of this type.

Lai and Hwang [30] also recognised that fuzzy linear programming (FLP) problems differ from possibilistic linear programming (PLP) problems because FLP connects fuzzy input data through a subjective preference-based membership function, while PLP correlates imprecise data by means of possibility distributions in which the latter are an analogue of probability distributions that are either objective or subjective by nature.
TABLE 1: Notation for decision variables of the fuzzy APP model.

\begin{tabular}{ll}
\hline $\begin{array}{l}\text { Decision } \\
\text { variable }\end{array}$ & Definition \\
\hline$P_{r t}^{n}$ & $\begin{array}{l}\text { Regular-time production of } n \text {th product in period } t \\
\text { (units) }\end{array}$ \\
$P_{o t}^{n}$ & Overtime production of $n$th product in period $t$ (units) \\
$W_{t}^{n}$ & Workforce level of $n$th product in period $t$ (man-day) \\
$I_{t}^{n}$ & Inventory level of $n$th product in period $t$ (units) \\
$B_{t}^{n}$ & Backorder level of $n$th product in period $t$ (units) \\
$H_{t}^{n}$ & Worker hired of $n$th product in period $t$ (man-day) \\
$L_{t}^{n}$ & Worker layoff of $n$th product in period $t$ (man-day) \\
\hline
\end{tabular}

2.2. Fuzzy Multiproduct APP. The investigated APP problem in this paper originates from the study previously conducted by Lai and Hwang [30]. We consider a multiproduct manufacturer that aims to satisfy the market demand over a medium planning horizon $T$. The management aims to efficiently satisfy the forecasted demand and thus adopts APP in an attempt to determine the optimum of inventory levels, production rates, overtime work, subcontracting rates, and other factors. In particular, the challenge is to determine a feasible method of adjusting the above factors appropriately such that the total costs are minimised and the market demand is satisfied. The forecasted demand may either be met or backordered [30]. At least one of the backorders and inventory levels in a period must be zero because it is crucial that any backorder be met within the following period. Furthermore, during any period, either net hiring or net firing may occur but not both. A fuzzy decision model is thus constructed to solve this problem following a subset of Lai and Hwang's assumptions [30].

(1) The product quantities include those of regular-time production, overtime production, production due to hiring additional employees, and those required to meet the demands.

(2) The initial inventory refers to the level of inventory that is necessary for initiating an order.

(3) The initial level of workforce for the production is known to the decision maker.

(4) The processing of successive orders does not induce setup costs.

(5) The finished goods in process can be stored in the inventory storage space.

(6) The new employees are equally productive as the old employees, indicating the presence of a reliable workforce pool. The new employees are assumed to be as fully productive as the old employees when they begin work.

Tables 1 and 2 list the decision variables and parameters of the proposed model. Notably, the first 10 sets of parameters listed in Table 2 are assumed to be fuzzy without loss of generality. 
TABLE 2: Notation for parameters of the fuzzy APP model.

\begin{tabular}{|c|c|}
\hline \multicolumn{2}{|c|}{ Parameter Definition } \\
\hline$\widetilde{C}_{p t}^{n}$ & $\begin{array}{l}\text { Unit production cost excluding labour cost of } n \text {th } \\
\text { product in period } t \text { (\$/unit) }\end{array}$ \\
\hline$\widetilde{C}_{o t}^{n}$ & $\begin{array}{l}\text { Overtime labour cost of } n \text {th product in period } t \\
(\$ / \text { man-hour) }\end{array}$ \\
\hline$\widetilde{C}_{r t}^{n}$ & Labour cost of $n$th product in period $t$ ( $\$ /$ man-day) \\
\hline$\widetilde{C}_{i t}^{n}$ & $\begin{array}{l}\text { Inventory carrying cost of } n \text {th product in period } t \\
\text { (\$/unit-period) }\end{array}$ \\
\hline$\widetilde{C}_{h t}^{n}$ & $\begin{array}{l}\text { Cost to hire one worker of } n \text {th product in period } t \\
(\$ / \text { man-day) }\end{array}$ \\
\hline$\widetilde{C}_{l t}^{n}$ & $\begin{array}{l}\text { Cost to layoff one worker of } n \text {th product in period } t \\
(\$ / \text { man-day) }\end{array}$ \\
\hline$\widetilde{C}_{b t}^{n}$ & Unit backorder cost of $n$th product in period $t$ ( $\$ /$ unit) \\
\hline$\tilde{k}_{n}$ & $\begin{array}{l}\text { Conversion factor in hours of labour per unit of } \\
\text { production (man-hour/unit) }\end{array}$ \\
\hline$\delta$ & $\begin{array}{l}\text { Regular working hours per worker per day } \\
\text { (man-hour/man-day) }\end{array}$ \\
\hline$\beta_{t}^{n}$ & $\begin{array}{l}\text { Fraction of working hours available for overtime } \\
\text { production }\end{array}$ \\
\hline$T$ & Planning horizon or number of periods \\
\hline$I_{0}^{n}$ & Initial inventory level of $n$th product (units) \\
\hline$W_{0}^{n}$ & Initial work force level of $n$th product (man-day) \\
\hline$B_{0}^{n}$ & Initial backorder level of $n$th product (units) \\
\hline$\left(\widetilde{W}_{t}^{\max }\right)_{n}$ & $\begin{array}{l}\text { Maximum workforce available of } n \text {th product in period } \\
t \text { (man-day) }\end{array}$ \\
\hline$\left(F_{t}^{\min }\right)_{n}$ & $\begin{array}{l}\text { Minimum demand of the } n \text {th product in period } t \\
\text { (units) }\end{array}$ \\
\hline$N$ & The number of products \\
\hline
\end{tabular}

2.2.1. Objective Function. The objective is to minimise the total incurred cost including the following:

(i) the total production cost: $\sum_{n=1}^{N} \sum_{t=1}^{T} \widetilde{C}_{p t}^{n}\left(P_{r t}^{n}+P_{o t}^{n}\right)$;

(ii) the total labour cost: $\sum_{n=1}^{N} \sum_{t=1}^{T}\left[\widetilde{C}_{r t}^{n} W_{t}^{n}+\widetilde{C}_{o t}^{n}\left(\widetilde{k}_{n} P_{o t}^{n}\right)\right]$, where $\widetilde{k}_{n}$ is a conversion factor for transforming the unit of $P_{o t}^{n}$ to man-hours (refer to Table 2);

(iii) the total inventory carrying cost: $\sum_{n=1}^{N} \sum_{t=1}^{T} \widetilde{C}_{i t}^{n} I_{t}^{n}$;

(iv) the total backorder cost: $\sum_{n=1}^{N} \sum_{t=1}^{T} \sum \widetilde{C}_{b t}^{n} B_{t}^{n}$;

(v) the total costs of changes in labour levels, including the costs to hire and layoff workers: $\sum_{n=1}^{N} \sum_{t=1}^{T}\left(\widetilde{C}_{h t}^{n} H_{t}^{n}+\widetilde{C}_{l t}^{n} L_{t}^{n}\right)$, where $H_{t}^{n} L_{t}^{n}=0, \forall n, t$, indicating that either net hiring or net firing of labour occurs during a period but not both [30].

2.2.2. General Constraints. The following constraints are considered for each product and time period.

\section{(1) Labour Level Constraints}

(i) The workforce level should not be greater than the maximum available workforce level during any period: $W_{t}^{n} \leq\left(\widetilde{W}_{t}^{\max }\right)_{n}, \forall n, t$. (ii) The workforce level in this period should be equal to the workforce level in the preceding period plus the new hires $\left(H_{t}^{n}\right)$ minus the layoffs $\left(L_{t}^{n}\right): W_{t}^{n}=W_{t-1}^{n}+$ $H_{t}^{n}-L_{t}^{n}, \forall n, t$, where $H_{t}^{n} L_{t}^{n}=0, \forall n, t$.

(iii) The regular-time production capacity should not be larger than the available labour capacity: $\widetilde{k}_{n} P_{r t}^{n}-$ $\delta W_{t}^{n} \leq 0, \forall n, t$, where $\widetilde{k}_{n}$ and $\delta$ are conversion factors for transforming a unit of $P_{r t}^{n}$ and $W_{t}^{n}$ to man-hours, respectively (refer to Table 2 ).

(iv) The variation in a workforce should not exceed the permitted level of the company policy during any period: $\widetilde{k}_{n} P_{o t}^{n}-\beta_{t}^{n}\left(\delta W_{t}^{n}\right) \leq 0, \forall n, t$, where $\widetilde{k}_{n}$ and $\delta$ are the same as those described above.

(2) Capacity Constraints. At the end of each time period, either a net inventory or backorder will occur but not both. Therefore, the statement that the total available product quantity should be equal to or greater than the minimum demand in period $t$ can be written as

$$
P_{r t}^{n}+P_{o t}^{n}+I_{t-1}^{n}-B_{t-1}^{n} \geq\left(F_{t}^{\mathrm{min}}\right)_{n}, \quad \forall n, t,
$$

where $I_{t}^{n} B_{t}^{n}=0, \forall n, t$, indicating that the demand over a particular period can be either met or backordered but not both.

(3) Inventory Level Constraints. In a similar manner, either a net inventory or backorder will occur during a period but not both. Therefore, the fundamental material quantity balance $[30,31,45]$ can be written as

$$
I_{t}^{n}-B_{t}^{n}=I_{t-1}^{n}-B_{t-1}^{n}+P_{r t}^{n}+P_{o t}^{n}-\widetilde{F}_{t}^{n}, \quad \forall n, t,
$$

where $I_{t}^{n} B_{t}^{n}=0, \forall n, t$. This equality indicates that the inventory level or backorder level in this period is equal to that of the preceding period plus the regular-time and overtime production and minus the forecasted demand. This equation ensures that the amount of each product sold in a period plus the inventory (or backorder) at the end of the period equals the total supply consisting of inventory (or backorder) from the previous period plus the regular and overtime production in the current period $[37,46]$.

2.2.3. The Proposed Model. By incorporating the above objective function, general constraints, and nonnegative constraints $P_{r t}^{n}, P_{o t}^{n}, W_{t}^{n}, I_{t}^{n}, B_{t}^{n}, H_{t}^{n}, L_{t}^{n} \geq 0, \forall n, t$, the proposed fuzzy multiproduct APP model can be constructed as follows [30]:

$$
\begin{array}{cc}
\widetilde{Z}=\min . & \sum_{n=1}^{N} \sum_{t=1}^{T}\left[\widetilde{C}_{p t}^{n}\left(P_{r t}^{n}+P_{o t}^{n}\right)+\widetilde{C}_{r t}^{n} W_{t}^{n}\right. \\
& +\widetilde{C}_{o t}^{n}\left(\widetilde{k}_{n} P_{o t}^{n}\right)+\widetilde{C}_{i t}^{n} I_{t}^{n} \\
& \left.+\widetilde{C}_{b t}^{n} B_{t}^{n}+\widetilde{C}_{h t}^{n} H_{t}^{n}+\widetilde{C}_{l t}^{n} L_{t}^{n}\right] \\
\text { s.t. } & W_{t}^{n} \leq\left(\widetilde{W}_{t}^{\max }\right)_{n}, \quad \forall n, t, \\
& W_{t}^{n}-W_{t-1}^{n}-H_{t}^{n}+L_{t}^{n}=0, \quad \forall n, t,
\end{array}
$$




$$
\begin{aligned}
& \widetilde{k}_{n} P_{r t}^{n}-\delta W_{t}^{n} \leq 0, \quad \forall n, t, \\
& \widetilde{k}_{n} P_{o t}^{n}-\beta_{t}^{n} \delta W_{t}^{n} \leq 0, \quad \forall n, t, \\
& P_{r t}^{n}+P_{o t}^{n}+I_{t-1}^{n}-B_{t-1}^{n} \geq\left(F_{t}^{\mathrm{min}}\right)_{n}, \quad \forall n, t, \\
& I_{t-1}^{n}-B_{t-1}^{n}+P_{r t}^{n}+P_{o t}^{n}-I_{t}^{n}+B_{t}^{n}=\widetilde{F}_{t}^{n}, \quad \forall n, t, \\
& P_{r t}^{n}, P_{o t}^{n}, W_{t}^{n}, I_{t}^{n}, B_{t}^{n}, H_{t}^{n}, L_{t}^{n} \geq 0, \quad \forall n, t .
\end{aligned}
$$

It is clear that Model (5) is intrinsically a linear programming (LP) model. Therefore, no requirement exists to enforce two sets of constraints, $I_{t}^{n} B_{t}^{n}=0$ and $H_{t}^{n} L_{t}^{n}=0$, on Model (5) because according to the complementary slackness theory of LP [44], the basic solution to Model (5) has a special structure that does not allow $I_{t}^{n}$ and $B_{t}^{n}$ to exist as basic variables at the same time, as is also true for $H_{t}^{n}$ and $L_{t}^{n}$.

\section{The Solution Procedure}

Because Model (5) is a FLP model, it can be solved using the existing FLP solution methods. However, as is generally known, most of the results obtained from these methods are crisp rather than fuzzy, an outcome that will result in the loss of certain important fuzzy information and undermine the quality of the APP. To overcome this shortcoming and conserve the fuzzy information, Chen and Huang [37] proposed a solution method for single-product APP problems with fuzzy parameters on the right-hand side of the general constraints. However, Model (5), an FLP with several parameters in the objective function and the coefficients of the general constraints, is more complicated than the model conducted by Chen and Huang [37]; therefore, it deserves further investigation.

In Model (5), many parameters are approximately known and can be described by fuzzy numbers [26]. For example, the forecasted demands $\left(\widetilde{F}_{t}^{n}\right)$ are stated as

$$
\widetilde{F}_{t}^{n}=\left\{\left(f_{t}^{n}, \mu_{\widetilde{F}_{t}^{n}}\left(f_{t}^{n}\right)\right) \mid f_{t}^{n} \in S\left(\widetilde{F}_{t}^{n}\right)\right\}, \quad \forall n, t,
$$

where $\mu_{\widetilde{F}_{t}^{n}}\left(f_{t}^{n}\right)$ is the membership function and $S(\cdot)$ is the support of the fuzzy number that denotes the universal set of the forecasted demands. Other fuzzy parameters can be described by the following fuzzy numbers in the same manner:

$$
\begin{array}{ll}
\widetilde{C}_{p t}^{n}=\left\{\left(c_{p t}^{n}, \mu_{\widetilde{C}_{p t}^{n}}\left(c_{p t}^{n}\right)\right) \mid c_{p t}^{n} \in S\left(\widetilde{C}_{p t}^{n}\right)\right\}, \quad \forall n, t, \\
\widetilde{C}_{o t}^{n}=\left\{\left(c_{o t}^{n}, \mu_{\widetilde{C}_{o t}^{n}}\left(c_{o t}^{n}\right)\right) \mid c_{o t}^{n} \in S\left(\widetilde{C}_{o t}^{n}\right)\right\}, \quad \forall n, t, \\
\widetilde{C}_{r t}^{n}=\left\{\left(c_{r t}^{n}, \mu_{\widetilde{C}_{r t}^{n}}\left(c_{r t}^{n}\right)\right) \mid c_{r t}^{n} \in S\left(\widetilde{C}_{r t}^{n}\right)\right\}, \quad \forall n, t, \\
\widetilde{C}_{i t}^{n}=\left\{\left(c_{i t}^{n}, \mu_{\widetilde{C}_{i t}^{n}}\left(c_{i t}^{n}\right)\right) \mid c_{i t}^{n} \in S\left(\widetilde{C}_{i t}^{n}\right)\right\}, \quad \forall n, t, \\
\widetilde{C}_{h t}^{n}=\left\{\left(c_{h t}^{n}, \mu_{\widetilde{C}_{h t}^{n}}\left(c_{h t}^{n}\right)\right) \mid c_{h t}^{n} \in S\left(\widetilde{C}_{h t}^{n}\right)\right\}, \quad \forall n, t, \\
\widetilde{C}_{l t}^{n}=\left\{\left(c_{l t}^{n}, \mu_{\widetilde{C}_{l t}^{n}}\left(c_{l t}^{n}\right)\right) \mid c_{l t}^{n} \in S\left(\widetilde{C}_{l t}^{n}\right)\right\}, \quad \forall n, t, \\
\widetilde{C}_{b t}^{n}=\left\{\left(c_{b t}^{n}, \mu_{\widetilde{C}_{b t}^{n}}\left(c_{b t}^{n}\right)\right) \mid c_{b t}^{n} \in S\left(\widetilde{C}_{b t}^{n}\right)\right\}, \quad \forall n, t,
\end{array}
$$

$$
\begin{gathered}
\widetilde{k}_{n}=\left\{\left(k_{n}, \mu_{\widetilde{k}_{n}}\left(k_{n}\right)\right) \mid k_{n} \in S\left(\widetilde{k}_{n}\right)\right\}, \quad \forall n, \\
\left(\widetilde{W}_{t}^{\max }\right)_{n} \\
=\left\{\left(\left(w_{t}^{\max }\right)_{n}, \mu_{\left(\widetilde{W}_{t}^{\max }\right)_{n}}\left(w_{t}^{\max }\right)_{n}\right)\right. \\
\left.\mid\left(w_{t}^{\max }\right)_{n} \in S\left(\left(\widetilde{W}_{t}^{\max }\right)_{n}\right)\right\}, \quad \forall n, t .
\end{gathered}
$$

According to Zadeh's extension principle, if certain parameters in Model (5) are fuzzy numbers, the minimum of the objective function $\widetilde{Z}$ is also a fuzzy number, and its membership function is defined as follows:

$\mu_{\widetilde{Z}}(Z)$

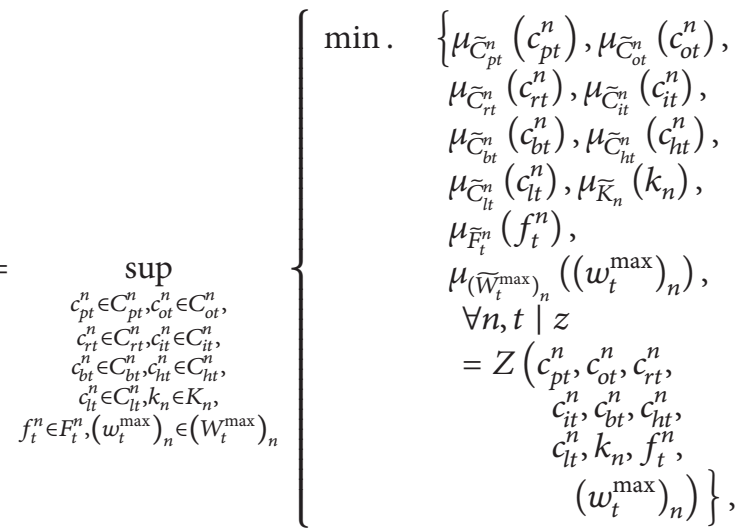

where $Z(\cdot)$ is the crisp objective value of Model (5) with the fuzzy parameters degenerated simultaneously to their crisp values. Equation (8) is theoretically correct, but it is not easy to use in practice.

Instead of directly using (8), this present paper uses the concept of parametric mathematical programming to find the membership function $\mu_{\widetilde{Z}}(Z)$. A pair of mathematical programs is developed to find the $\alpha$-cuts of $\widetilde{Z}$ based on Zadeh's extension principle. First, the definition of the $\alpha$-cut of a fuzzy number is briefly introduced. The $\alpha$-cut of the forecasted demand $\widetilde{F}_{t}^{n}$ is defined as follows [26]:

$$
\left(\widetilde{F}_{t}^{n}\right)_{\alpha}=\left\{f_{t}^{n} \in S\left(\widetilde{F}_{t}^{n}\right) \mid \mu_{\widetilde{F}_{t}^{n}}\left(f_{t}^{n}\right) \geq \alpha\right\} .
$$

Using $\alpha$-cuts, $\widetilde{F}_{t}^{n}$ can be represented by different possibility levels of the confidence intervals [26]. Therefore, the $\alpha$-cut of the fuzzy number $\widetilde{F}_{t}^{n}$ defined in (9) represent a crisp interval that can be expressed in the following form:

$$
\begin{aligned}
\left(\widetilde{F}_{t}^{n}\right)_{\alpha}= & {\left[\min _{f_{t}^{n} \in S\left(\widetilde{F}_{t}^{n}\right)}\left\{f_{t}^{n} \mid \mu_{\widetilde{F}_{t}^{n}}\left(f_{t}^{n}\right) \geq \alpha\right\},\right.} \\
& \left.\max _{f_{t}^{n} \in S\left(\widetilde{F}_{t}^{n}\right)}\left\{f_{t}^{n} \mid \mu_{\widetilde{F}_{t}^{n}}\left(f_{t}^{n}\right) \geq \alpha\right\}\right] \\
= & {\left[\left(F_{t}^{n}\right)_{\alpha}^{L},\left(F_{t}^{n}\right)_{\alpha}^{U}\right] . }
\end{aligned}
$$

This interval indicates where the value of $f_{t}^{n}$ lies at possibility level $\alpha$. Clearly, from Definition (8), the membership function 
$\mu_{\widetilde{Z}}$ is also parameterised by $\alpha$. Thus, one approach to constructing $\mu_{\widetilde{Z}}$ is the $\alpha$-cut approach.

Next, the $\alpha$-cuts of other fuzzy parameters can be, respectively, described as follows:

$$
\begin{array}{ll}
\left(\widetilde{C}_{p t}^{n}\right)_{\alpha}=\left[\left(C_{p t}^{n}\right)_{\alpha}^{L},\left(C_{p t}^{n}\right)_{\alpha}^{U}\right], & \left(\widetilde{C}_{o t}^{n}\right)_{\alpha}=\left[\left(C_{o t}^{n}\right)_{\alpha}^{L},\left(C_{o t}^{n}\right)_{\alpha}^{U}\right], \\
\left(\widetilde{C}_{r t}^{n}\right)_{\alpha}=\left[\left(C_{r t}^{n}\right)_{\alpha}^{L},\left(C_{r t}^{n}\right)_{\alpha}^{U}\right], \quad\left(\widetilde{C}_{i t}^{n}\right)_{\alpha}=\left[\left(C_{i t}^{n}\right)_{\alpha}^{L},\left(C_{i t}^{n}\right)_{\alpha}^{U}\right], \\
\left(\widetilde{C}_{h t}^{n}\right)_{\alpha}=\left[\left(C_{h t}^{n}\right)_{\alpha}^{L},\left(C_{h t}^{n}\right)_{\alpha}^{U}\right], \quad\left(\widetilde{C}_{l t}^{n}\right)_{\alpha}=\left[\left(C_{l t}^{n}\right)_{\alpha}^{L},\left(C_{l t}^{n}\right)_{\alpha}^{U}\right], \\
\left(\widetilde{C}_{b t}^{n}\right)_{\alpha}=\left[\left(C_{b t}^{n}\right)_{\alpha}^{L},\left(C_{b t}^{n}\right)_{\alpha}^{U}\right], \quad\left(\widetilde{k}_{n}\right)_{\alpha}=\left[\left(k_{n}\right)_{\alpha}^{L},\left(k_{n}\right)_{\alpha}^{U}\right], \\
\left(\left(\widetilde{W}_{t}^{\max }\right)_{n}\right)_{\alpha}=\left[\left(\left(W_{t}^{\max }\right)_{n}\right)_{\alpha}^{L},\left(\left(\widetilde{W}_{t}^{\max }\right)_{n}\right)_{\alpha}^{U}\right] .
\end{array}
$$

The $\alpha$-cut approach is intended to derive the $\alpha$-cuts of $\mu_{\widetilde{Z}}(Z)$ or, in other words, to derive the crisp interval $\left[Z_{\alpha}^{L}, Z_{\alpha}^{U}\right]$ for all $\alpha \in[0,1]$. This derivation will be introduced later. According to Zadeh's extension principle [38, 39], the $\widetilde{Z}$ defined in (8) is a fuzzy number that possesses convexity [26].
Consequently, according to the attractive feature that all $\alpha$ cuts form a nested structure with respect to $\alpha$ [47], the set of intervals $\left\{\left[Z_{\alpha}^{L}, Z_{\alpha}^{U}\right] \mid \alpha \in[0,1]\right\}$ builds the approximated membership function of $\widetilde{Z}$ by enumerating different values of $\alpha$.

According to Definition (8), $\mu_{\widetilde{Z}}(Z)$ is the minimum of these 10 sets of membership functions of fuzzy parameters (e.g., $\mu_{\widetilde{C}_{p t}^{n}}\left(c_{p t}^{n}\right)$ and $\mu_{\widetilde{C}_{o t}^{n}}\left(c_{o t}^{n}\right)$ ), which complicates the situation. Thus, to derive the crisp interval of $\left[Z_{\alpha}^{L}, Z_{\alpha}^{U}\right]$ and address the membership value, all of the membership values of these 10 sets of fuzzy parameters that are not smaller than $\alpha$ are required, and at least one of them must be equal to $\alpha$ such that $z=Z\left(c_{p t}^{n}, c_{o t}^{n}, c_{r t}^{n}, c_{i t}^{n}, c_{b t}^{n}, c_{h t}^{n}, c_{l t}^{n}, k_{n}, f_{t}^{n},\left(w_{t}^{\max }\right)_{n}\right)$ to satisfy $\mu_{\widetilde{Z}}(Z)=\alpha$. It is clear that the membership function $\mu_{\widetilde{Z}}(Z)$ can be defined by determining the left-shape function and the right-shape function of $\mu_{\widetilde{Z}}(Z)$. Based on this idea, the lower bound $Z_{\alpha}^{L}$ and upper bound $Z_{\alpha}^{U}$ of $\mu_{\widetilde{Z}}(Z)$ can be derived using the solution of the following pair of two-level mathematical programs $[40,41]$ :

$$
\begin{aligned}
& \int \min . \quad \sum_{n=1}^{N} \sum_{t=1}^{T}\left[c_{p t}^{n}\left(P_{r t}^{n}+P_{o t}^{n}\right)+c_{r t}^{n} W_{t}^{n}+c_{o t}^{n}\left(\widetilde{k}_{n} P_{o t}^{n}\right)+c_{i t}^{n} I_{t}^{n}+c_{b t}^{n} B_{t}^{n}+c_{h t}^{n} H_{t}^{n}+c_{l t}^{n} L_{t}^{n}\right] \\
& \text { s.t. } \quad W_{t}^{n} \leq\left(w_{t}^{\max }\right)_{n}, \quad \forall n, t \text {, } \\
& W_{t}^{n}-W_{t-1}^{n}-H_{t}^{n}+L_{t}^{n}=0, \quad \forall n, t, \\
& k_{n} P_{r t}^{n}-\delta W_{t}^{n} \leq 0, \quad \forall n, t \text {, } \\
& k_{n} P_{o t}^{n}-\beta_{t}^{n} \delta W_{t}^{n} \leq 0, \quad \forall n, t \text {, } \\
& P_{r t}^{n}+P_{o t}^{n}+I_{t-1}^{n}-B_{t-1}^{n} \geq\left(F_{t}^{\min }\right)_{n}, \quad \forall n, t, \\
& I_{t-1}^{n}-B_{t-1}^{n}+P_{r t}^{n}+P_{o t}^{n}-I_{t}^{n}+B_{t}^{n}=f_{t}^{n}, \quad \forall n, t, \\
& P_{r t}^{n}, P_{o t}^{n}, W_{t}^{n}, I_{t}^{n}, B_{t}^{n}, H_{t}^{n}, L_{t}^{n} \geq 0, \quad \forall n, t \text {. }
\end{aligned}
$$

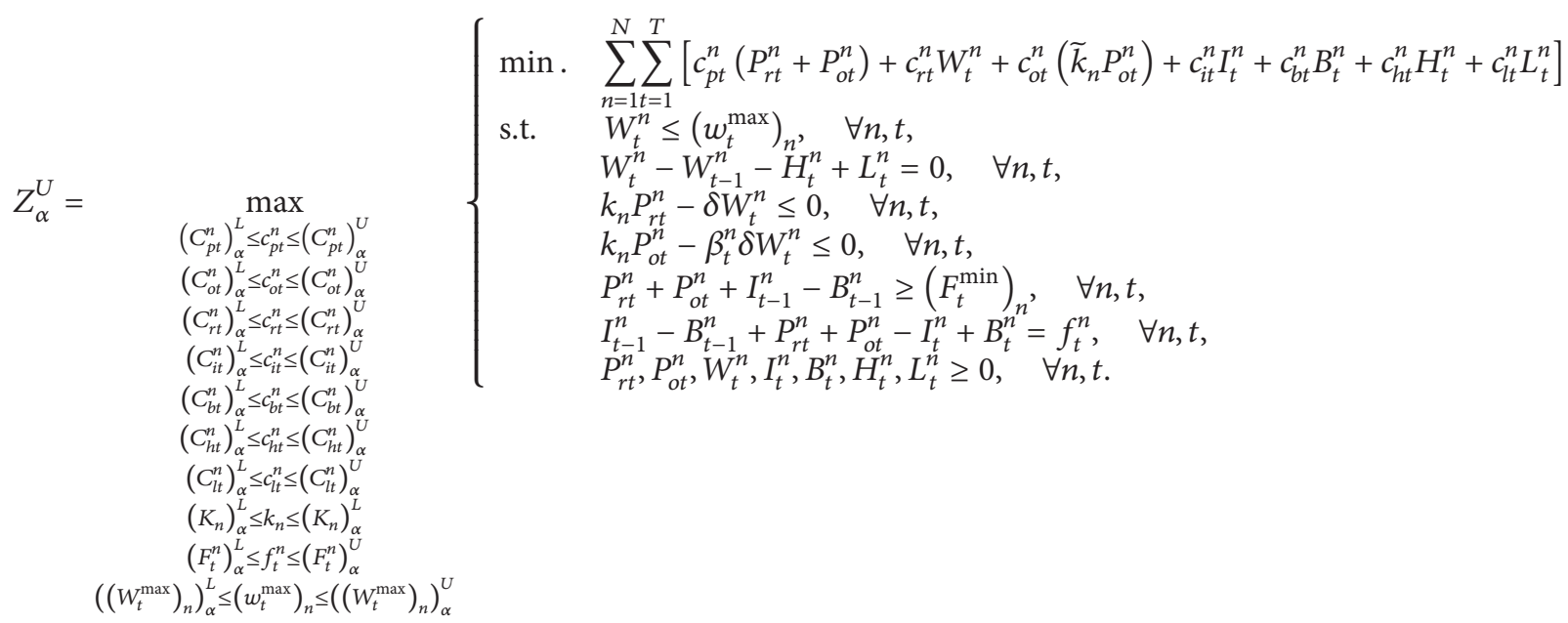

To satisfy $\mu_{Z}(z)=\alpha$ as required by Definition (8), at least one of $c_{p t}^{n}, c_{o t}^{n}, c_{r t}^{n}, c_{i t}^{n}, c_{b t}^{n}, c_{h t}^{n}, c_{l t}^{n}, k_{n}, f_{t}^{n}$, and $\left(w_{t}^{\max }\right)_{n}$ must meet the boundary of their $\alpha$-cuts. For Model (12a), $\left(w_{t}^{\max }\right)_{n}$ can be directly set to its upper bound $\left(\left(W_{t}^{\max }\right)_{n}\right)_{\alpha}^{U}, \forall n, t$, 
because it defines the largest feasible region as $\left(\left(W_{t}^{\max }\right)_{n}\right)_{\alpha}^{L} \leq$ $w_{n t}^{\max } \leq\left(\left(W_{t}^{\max }\right)_{n}\right)_{\alpha}^{U}$. Furthermore, because this model aims to find the minimum of all minimum objective values, the constraints of the first level can be inserted into the second level to transform the two-level mathematical program of Model (12a) into the following classical one-level mathematical program:

$$
\begin{aligned}
& Z_{\alpha}^{L}=\min . \quad \sum_{n=1}^{N} \sum_{t=1}^{T}\left[c_{p t}^{n}\left(P_{r t}^{n}+P_{o t}^{n}\right)\right. \\
& +c_{r t}^{n} W_{t}^{n}+c_{o t}^{n}\left(k_{n} P_{o t}^{n}\right)+c_{i t}^{n} I_{t}^{n} \\
& \left.+c_{b t}^{n} B_{t}^{n}+c_{h t}^{n} H_{t}^{n}+c_{l t}^{n} L_{t}^{n}\right] \\
& \text { s.t. } \quad W_{t}^{n} \leq\left(\left(W_{t}^{\max }\right)_{n}\right)_{\alpha}^{U}, \quad \forall n, t \text {, } \\
& W_{t}^{n}-W_{t-1}^{n}-H_{t}^{n}+L_{t}^{n}=0, \quad \forall n, t, \\
& k_{n} P_{r t}^{n}-\delta W_{t}^{n} \leq 0, \quad \forall n, t, \\
& k_{n} P_{o t}^{n}-\beta_{t}^{n} \delta W_{t}^{n} \leq 0, \quad \forall n, t, \\
& P_{r t}^{n}+P_{o t}^{n}+I_{t-1}^{n}-B_{t-1}^{n} \geq\left(F_{t}^{\min }\right)_{n}, \\
& \forall n, t \text {, } \\
& I_{t-1}^{n}-B_{t-1}^{n}+P_{r t}^{n}+P_{o t}^{n}-I_{t}^{n}+B_{t}^{n}=f_{t}^{n}, \\
& \forall n, t \text {, } \\
& \left(C_{p t}^{n}\right)_{\alpha}^{L} \leq c_{p t}^{n} \leq\left(C_{p t}^{n}\right)_{\alpha}^{U}, \\
& \left(C_{o t}^{n}\right)_{\alpha}^{L} \leq c_{o t}^{n} \leq\left(C_{o t}^{n}\right)_{\alpha}^{U}, \\
& \forall n, t \text {, }
\end{aligned}
$$

$$
\begin{gathered}
\left(C_{r t}^{n}\right)_{\alpha}^{L} \leq c_{r t}^{n} \leq\left(C_{r t}^{n}\right)_{\alpha}^{U}, \\
\left(C_{i t}^{n}\right)_{\alpha}^{L} \leq c_{i t}^{n} \leq\left(C_{i t}^{n}\right)_{\alpha}^{U}, \\
\forall n, t \\
\left(C_{b t}^{n}\right)_{\alpha}^{L} \leq c_{b t}^{n} \leq\left(C_{b t}^{n}\right)_{\alpha}^{U}, \\
\left(C_{h t}^{n}\right)_{\alpha}^{L} \leq c_{h t}^{n} \leq\left(C_{h t}^{n}\right)_{\alpha}^{U}, \\
\quad \forall n, t, \\
\left(C_{l t}^{n}\right)_{\alpha}^{L} \leq c_{l t}^{n} \leq\left(C_{l t}^{n}\right)_{\alpha}^{U}, \\
\left(F_{t}^{n}\right)_{\alpha}^{L} \leq f_{t}^{n} \leq\left(F_{t}^{n}\right)_{\alpha}^{U}, \\
\quad \forall n, t, \\
\left(K_{n}\right)_{\alpha}^{L} \leq k_{n} \leq\left(K_{n}\right)_{\alpha}^{U}, \quad \forall n, \\
P_{r t}^{n}, P_{o t}^{n}, W_{t}^{n}, I_{t}^{n}, B_{t}^{n}, H_{t}^{n}, L_{t}^{n} \geq 0, \quad \forall n, t .
\end{gathered}
$$

This model is a classical linear program that can be solved easily using LP solvers. Because all $\left(w_{t}^{\max }\right)_{n}, \forall n, t$, have been set to the upper bound of their $\alpha$-cut in this model, $\mu_{Z}(z)=\alpha$ is guaranteed, as required by Definition (8) based on Zadeh's extension principle.

For Model (12b), however, because the first level is a maximisation problem that is not consistent with the minimisation operation of the second level, the constraints of the first level cannot be directly inserted into the second level. To address this situation, the dual of the second-level problem is formulated as consistent with the maximisation operation of the first level. According to the duality theorem of LP, it is well known that the primal and dual models share the same objective value [42]. Consequently, Model (12b) can be reformulated as follows:

$$
\begin{aligned}
& \begin{cases}\max & \sum_{n=1}^{N} \sum_{t=1}^{T}\left[-w_{n t}^{\max } A_{t}^{n}-W_{0}^{n} N_{1}^{n}+\left(F_{t}^{\min }\right)_{n} G_{t}^{n}+f_{t}^{n} M_{t}^{n}\right] \\
\text { s.t. } \quad & -k_{n} D_{t}^{n}+G_{t}^{n}+M_{t}^{n} \leq c_{p t}^{n}, \quad \forall n, t, \\
& -k_{n} E_{t}^{n}+G_{t}^{n}+M_{t}^{n} \leq c_{p t}^{n}+k_{n} c_{o t}^{n}, \quad \forall n, t, \\
& -A_{t}^{n}-N_{t}^{n}+B_{t+1}^{n}+\delta D_{t}^{n}+\beta_{t}^{n} \delta E_{t}^{n} \leq c_{r t}^{n}, \quad \forall n ; t=1,2, \ldots, T-1, \\
& -A_{T}^{n}-N_{T}^{n}+\delta D_{T}^{n}+\beta_{T}^{n} \delta E_{T}^{n} \leq c_{r T}^{n}, \quad \forall n,\end{cases} \\
& Z_{\alpha}^{U}= \\
& \max \\
& \left(C_{p t}^{n}\right)_{\alpha}^{L} \leq c_{p t}^{n} \leq\left(C_{p t}^{n}\right)_{\alpha}^{U} \\
& \left(C_{o t}^{n}\right)_{\alpha}^{L} \leq c_{o t}^{n} \leq\left(C_{o t}^{n}\right)_{\alpha}^{U} \\
& \left(C_{r t}^{n}\right)_{\alpha}^{L} \leq c_{r t}^{n} \leq\left(C_{r t}^{n}\right)_{\alpha}^{U} \\
& \left(C_{i t}^{n}\right)_{\alpha}^{L} \leq c_{i t}^{n} \leq\left(C_{i t}^{n}\right)_{\alpha}^{U} \\
& \left(C_{b t}^{n}\right)_{\alpha}^{L} \leq c_{b t}^{n} \leq\left(C_{b t}^{n}\right)_{\alpha}^{U} \\
& \left(C_{h t}^{n}\right)_{\alpha}^{L} \leq c_{h t}^{n} \leq\left(C_{h t}^{n}\right)_{\alpha}^{U} \\
& \left(C_{l t}^{n}\right)_{\alpha}^{L} \leq c_{l t}^{n} \leq\left(C_{l t}^{n}\right)_{\alpha}^{U} \\
& \left(K_{n}\right)_{\alpha}^{L} \leq k_{n} \leq\left(K_{n}\right)_{\alpha}^{L} \\
& \left(F_{t}^{n}\right)_{\alpha}^{L} \leq f_{t}^{n} \leq\left(F_{t}^{n}\right)_{\alpha}^{U} \\
& G_{t+1}^{n}-M_{t}^{n}+H_{t+1}^{n} \leq c_{i t}^{n}, \quad \forall n ; t=1,2, \ldots, T-1 \text {, } \\
& -M_{T}^{n} \leq c_{i T}^{n}, \quad M_{T}^{n} \leq c_{b T}^{n}, \quad \forall n, \\
& -G_{t+1}^{n}+M_{t}^{n}-M_{t+1}^{n} \leq c_{b t}^{n}, \quad \forall n ; t=1,2, \ldots, T-1, \\
& N_{t}^{n} \leq c_{h t}^{n}, \quad-N_{t}^{n} \leq c_{l t}^{n}, \quad \forall n, t \\
& A_{t}^{n}, D_{t}^{n}, E_{t}^{n}, G_{t}^{n} \geq 0, \quad \forall n, t \text {, } \\
& N_{t}^{n}, M_{t}^{n} \text { unrestricted in sign, } \forall n, t \text {, }
\end{aligned}
$$


where $A_{t}^{n}, N_{t}^{n}, D_{t}^{n}, E_{t}^{n}, G_{t}^{n}$, and $M_{t}^{n}, \forall n, t$, are the sets of dual variables defined for the first to sixth sets of constraints in Model (12b), respectively.

Similar to the lower bound case, in Model (14), the upper bound of the objective value can be derived by setting $\left(w_{t}^{\max }\right)_{n}=\left(\left(W_{t}^{\max }\right)_{n}\right)_{\alpha}^{L}, \forall n, t$, which yields the largest feasible region. Furthermore, because both the first and second levels perform the same maximisation operation, their constraints can be combined to form a classical mathematical program. Consequently, Model (14) can be rewritten as

$$
\begin{aligned}
& Z_{\alpha}^{U}=\max \sum_{n=1}^{N} \sum_{t=1}^{T}\left[-\left(\left(W_{t}^{\max }\right)_{n}\right)_{\alpha}^{L} A_{t}^{n}\right. \\
& \left.-W_{0}^{n} N_{1}^{n}+\left(F_{t}^{\min }\right)_{n} G_{t}^{n}+f_{t}^{n} M_{t}^{n}\right] \\
& \text { s.t. } \quad-k_{n} D_{t}^{n}+G_{t}^{n}+M_{t}^{n} \leq c_{p t}^{n}, \quad \forall n, t \text {, } \\
& -k_{n} E_{t}^{n}+G_{t}^{n}+M_{t}^{n} \leq c_{p t}^{n}+k_{n} c_{o t}^{n}, \quad \forall n, t, \\
& -A_{t}^{n}-N_{t}^{n}+B_{t+1}^{n}+\delta D_{t}^{n}+\beta_{t}^{n} \delta E_{t}^{n} \leq c_{r t}^{n} \text {, } \\
& \forall n ; \quad t=1,2, \ldots, T-1, \\
& -A_{T}^{n}-N_{T}^{n}+\delta D_{T}^{n}+\beta_{T}^{n} \delta E_{T}^{n} \leq c_{r T}^{n}, \quad \forall n, \\
& G_{t+1}^{n}-M_{t}^{n}+H_{t+1}^{n} \leq c_{i t}^{n}, \\
& \forall n ; \quad t=1,2, \ldots, T-1, \\
& -M_{T}^{n} \leq c_{i T}^{n}, \quad M_{T}^{n} \leq c_{b T}^{n}, \quad \forall n, \\
& -G_{t+1}^{n}+M_{t}^{n}-M_{t+1}^{n} \leq c_{b t}^{n}, \\
& \forall n ; \quad t=1,2, \ldots, T-1, \\
& N_{t}^{n} \leq c_{h t}^{n}, \quad-N_{t}^{n} \leq c_{l t}^{n}, \quad \forall n, t, \\
& \left(C_{p t}^{n}\right)_{\alpha}^{L} \leq c_{p t}^{n} \leq\left(C_{p t}^{n}\right)_{\alpha}^{U}, \\
& \left(C_{o t}^{n}\right)_{\alpha}^{L} \leq c_{o t}^{n} \leq\left(C_{o t}^{n}\right)_{\alpha}^{U}, \quad \forall n, t, \\
& \left(C_{r t}^{n}\right)_{\alpha}^{L} \leq c_{r t}^{n} \leq\left(C_{r t}^{n}\right)_{\alpha}^{U}, \\
& \left(C_{i t}^{n}\right)_{\alpha}^{L} \leq c_{i t}^{n} \leq\left(C_{i t}^{n}\right)_{\alpha}^{U}, \quad \forall n, t, \\
& \left(C_{b t}^{n}\right)_{\alpha}^{L} \leq c_{b t}^{n} \leq\left(C_{b t}^{n}\right)_{\alpha}^{U}, \\
& \left(C_{h t}^{n}\right)_{\alpha}^{L} \leq c_{h t}^{n} \leq\left(C_{h t}^{n}\right)_{\alpha}^{U}, \quad \forall n, t, \\
& \left(C_{l t}^{n}\right)_{\alpha}^{L} \leq c_{l t}^{n} \leq\left(C_{l t}^{n}\right)_{\alpha}^{U}, \\
& \left(K_{n}\right)_{\alpha}^{L} \leq k_{n} \leq\left(K_{n}\right)_{\alpha}^{U}, \quad \forall n, t, \\
& \left(F_{t}^{n}\right)_{\alpha}^{L} \leq f_{t}^{n} \leq\left(F_{t}^{n}\right)_{\alpha}^{U}, \quad \forall n, t, \\
& A_{t}^{n}, D_{t}^{n}, E_{t}^{n}, G_{t}^{n} \geq 0, \quad \forall n, t, \\
& N_{t}^{n}, M_{t}^{n} \text { unrestricted in sign, } \forall n, t \text {, }
\end{aligned}
$$

TABLE 3: Fuzzy unit production cost and labour cost.

\begin{tabular}{lcccc}
\hline Period $(t)$ & $\widetilde{C}_{p t}^{1}$ & $\widetilde{C}_{p t}^{2}$ & $\widetilde{C}_{r t}^{1}$ & $\widetilde{C}_{r t}^{2}$ \\
\hline 1 & $(18,18,20)$ & $(19,19,21)$ & $(60,60,64)$ & $(62,62,65)$ \\
2 & $(18,18,20)$ & $(19,19,21)$ & $(60,60,64)$ & $(62,62,65)$ \\
3 & $(19,19,21)$ & $(20,20,22)$ & $(62,62,65)$ & $(64,64,68)$ \\
4 & $(19,19,21)$ & $(20,20,22)$ & $(62,62,65)$ & $(64,64,68)$ \\
5 & $(20,20,22)$ & $(21,21,23)$ & $(64,64,69)$ & $(66,66,71)$ \\
6 & $(20,20,22)$ & $(21,21,23)$ & $(64,64,69)$ & $(66,66,71)$ \\
\hline
\end{tabular}

TABLE 4: Fuzzy overtime labour cost and inventory carrying cost.

\begin{tabular}{lcccc}
\hline Period $(t)$ & $\widetilde{C}_{o t}^{1}$ & $\widetilde{C}_{o t}^{2}$ & $\widetilde{C}_{i t}^{1}$ & $\widetilde{C}_{i t}^{2}$ \\
\hline 1 & $(15,15,17)$ & $(16,16,18)$ & $(1.8,1.8,2.0)$ & $(1.9,1.9,2.1)$ \\
2 & $(15,15,17)$ & $(16,16,18)$ & $(1.8,1.8,2.0)$ & $(1.9,1.9,2.1)$ \\
3 & $(16,16,18)$ & $(17,17,19)$ & $(1.9,1.9,2.1)$ & $(2.0,2.0,2.2)$ \\
4 & $(16,16,18)$ & $(17,17,19)$ & $(1.9,1.9,2.1)$ & $(2.0,2.0,2.2)$ \\
5 & $(17,17,19)$ & $(18,18,20)$ & $(2.0,2.0,2.2)$ & $(2.1,2.1,2.3)$ \\
6 & $(17,17,19)$ & $(18,18,20)$ & $(2.0,2.0,2.2)$ & $(2.1,2.1,2.3)$ \\
\hline
\end{tabular}

which is a linearly constrained nonlinear programming (NLP) model that can be solved using many efficient and effective solution methods, including the generalised reduced gradient (GRG) method and successive quadratic programming (SQP) [48].

The solution of Models (13) and (15) yields the crisp interval $\left[Z_{\alpha}^{L}, Z_{\alpha}^{U}\right]$. By enumerating different values of $\alpha$, the approximated membership function of $\widetilde{Z}$, or the fuzzy minimum total cost of the APP model, can be derived by numerically identifying the set of intervals $\left\{\left[Z_{\alpha}^{L}, Z_{\alpha}^{U}\right] \mid \alpha \epsilon\right.$ $[0,1]\}$. Meanwhile, the corresponding optimal APP is also completed.

Note that the minimum total cost obtained by adopting the proposed approach is a fuzzy performance measure. The significance of such a fuzzy performance measure is that it conserves the fuzziness of the input parameters; thus, it is able to more accurately represent a system with nonstochastic factors. Consequently, the proposed approach can obtain more realistic performance measures when certain parameters in the APP are fuzzy. These features are important and useful to the decision maker in practice.

\section{Numerical Application}

The following example inspired by previous studies illustrates the validity of the proposed model and solution procedure in this paper [30]. The example is a six-period (monthly base) APP problem involving two types of products with several parameters characterised by triangular fuzzy numbers as follows: (1) the unit production cost excluding labour cost, (2) overtime labour cost, (3) labour cost, (4) inventory carrying cost, (5) cost to hire one worker, (6) cost to lay off one worker, (7) unit backorder cost, (8) conversion factor in hours of labour, (9) forecasted demands, and (10) maximum workforce, as shown in Tables 3, 4, 5, 6, 7, and 8. The assumed trend for future demand is considered optimistic in periods 1 
TABLE 5: Fuzzy cost to hire and layoff one worker.

\begin{tabular}{lcccc}
\hline Period $(t)$ & $\widetilde{C}_{h t}^{1}$ & $\widetilde{C}_{h t}^{2}$ & $\widetilde{C}_{l t}^{1}$ & $\widetilde{C}_{l t}^{2}$ \\
\hline 1 & $(25,25,28)$ & $(26,26,28)$ & $(36,36,40)$ & $(37,37,41)$ \\
2 & $(25,25,28)$ & $(26,26,28)$ & $(36,36,40)$ & $(37,37,41)$ \\
3 & $(25,25,28)$ & $(26,26,28)$ & $(36,36,40)$ & $(37,37,41)$ \\
4 & $(25,25,28)$ & $(26,26,28)$ & $(36,36,40)$ & $(37,37,41)$ \\
5 & $(25,25,28)$ & $(26,26,28)$ & $(36,36,40)$ & $(37,37,41)$ \\
6 & $(25,25,28)$ & $(26,26,28)$ & $(36,36,40)$ & $(37,37,41)$ \\
\hline
\end{tabular}

TABLE 6: Fuzzy unit backorder cost and conversion factor.

\begin{tabular}{|c|c|c|c|c|}
\hline Period $(t)$ & $\widetilde{C}_{b t}^{1}$ & $\widetilde{C}_{b t}^{2}$ & $\tilde{k}_{1}$ & $\tilde{k}_{2}$ \\
\hline 1 & $(2.5,2.5,2.7)$ & $(2.7,2.7,3.0)$ & $(2.9,2.9,3.0)$ & $(3.0,3.0,3.1)$ \\
\hline 2 & $(2.5,2.5,2.7)$ & $(2.7,2.7,3.0)$ & $(2.9,2.9,3.0)$ & $(3.0,3.0,3.1)$ \\
\hline 3 & $(2.7,2.7,3.0)$ & $(2.8,2.8,3.2)$ & $(2.9,2.9,3.0)$ & $(3.0,3.0,3.1)$ \\
\hline 4 & $(2.7,2.7,3.0)$ & $(2.8,2.8,3.2)$ & $(2.9,2.9,3.0)$ & $(3.0,3.0,3.1)$ \\
\hline 5 & $(2.9,2.9,3.1)$ & $(3.1,3.1,3.4)$ & $(2.9,2.9,3.0)$ & $(3.0,3.0,3.1)$ \\
\hline 6 & $(2.9,2.9,3.1)$ & $(3.1,3.1,3.4)$ & $(2.9,2.9,3.0)$ & $(3.0,3.0,3.1)$ \\
\hline
\end{tabular}

TABle 7: Fuzzy demand.

\begin{tabular}{lcc}
\hline Period $(t)$ & $\widetilde{F}_{t}^{1}$ & $\widetilde{F}_{t}^{2}$ \\
\hline 1 & $(250,275,275)$ & $(260,280,280)$ \\
2 & $(285,330,330)$ & $(280,320,320)$ \\
3 & $(430,450,500)$ & $(420,480,520)$ \\
4 & $(260,300,320)$ & $(250,280,300)$ \\
5 & $(300,350,350)$ & $(310,340,340)$ \\
6 & $(270,340,340)$ & $(280,320,320)$ \\
\hline
\end{tabular}

and 2, pessimistic in periods 5 and 6 , and neutral in periods 3 and 4 . The example is further characterised by the following.

(i) The regular labour force works eight hours a day; that is, $\delta=8$.

(ii) The initial workforce consists of 100 workers for product 1 and 150 workers for product 2 ; that is, $W_{0}^{1}=$ 100 and $W_{0}^{2}=150$.

(iii) Overtime production is limited to no more than $30 \%$ of regular-time production; that is, $\beta_{t}^{n}=0.3, n=$ 1,$2 ; t=1, \ldots, 6$.

(iv) The initial inventories of products 1 and 2 are 0 ; that is, $I_{0}^{1}=0$ and $I_{0}^{2}=0$.

(v) Backorders must not be carried over for more than one period.

According to Model (5), this fuzzy multiproduct APP problem can be formulated as an LP model with many fuzzy
TABLE 8: Fuzzy maximum workforce.

\begin{tabular}{lcc}
\hline Period $(t)$ & $\left(\widetilde{W}_{t}^{\max }\right)_{1}$ & $\left(\widetilde{W}_{t}^{\max }\right)_{2}$ \\
\hline 1 & $(90,90,100)$ & $(100,100,120)$ \\
2 & $(100,100,115)$ & $(120,120,140)$ \\
3 & $(120,120,150)$ & $(130,130,160)$ \\
4 & $(120,120,150)$ & $(130,130,160)$ \\
5 & $(120,120,150)$ & $(130,130,160)$ \\
6 & $(120,120,150)$ & $(130,130,160)$ \\
\hline
\end{tabular}

parameters in the objective and constraints of the following form:

$$
\begin{aligned}
\widetilde{Z}=\min . & (18,18,20)\left(P_{r 1}^{1}+P_{o 1}^{1}\right)+(18,18,20)\left(P_{r 2}^{1}+P_{o 2}^{1}\right) \\
& +(19,19,21)\left(P_{r 3}^{1}+P_{o 3}^{1}\right)+(19,19,21)\left(P_{r 4}^{1}+P_{o 4}^{1}\right) \\
& +(20,20,22)\left(P_{r 5}^{1}+P_{o 5}^{1}\right)+(20,20,22)\left(P_{r 6}^{1}+P_{o 6}^{1}\right) \\
& +(60,60,64) W_{1}^{1}+(60,60,64) W_{2}^{1} \\
& +(62,62,65) W_{3}^{1}+(62,62,65) W_{4}^{1} \\
& +(64,64,69) W_{5}^{1}+(64,64,69) W_{6}^{1} \\
& +(15,15,17)(2.9,2.9,3.0) P_{o 1}^{1} \\
& +(15,15,17)(2.9,2.9,3.0) P_{o 2}^{1} \\
& +(16,16,18)(2.9,2.9,3.0) P_{o 3}^{1} \\
& +(16,16,18)(2.9,2.9,3.0) P_{o 4}^{1} \\
& +(17,17,19)(2.9,2.9,3.0) P_{o 5}^{1} \\
& +(17,17,19)(2.9,2.9,3.0) P_{o 6}^{1} \\
& +(1.8,1.8,2.0) I_{1}^{1}+(1.8,1.8,2.0) I_{2}^{1} \\
& +(1.9,1.9,2.1) I_{3}^{1}(1.9,1.9,2.1) I_{4}^{1} \\
& +(2.0,2.0,2.2) I_{5}^{1}+(2.0,2.0,2.2) I_{6}^{1} \\
& +(2.5,2.5,2.7) B_{1}^{1}+(2.5,2.5,2.7) B_{2}^{1} \\
& +(2.7,2.7,3.0) B_{3}^{1}+(2.7,2.7,3.0) B_{4}^{1} \\
& +(2.9,2.9,3.1) B_{5}^{1}+(2.9,2.9,3.1) B_{6}^{1} \\
& +(25,25,28) H_{1}^{1}+(25,25,28) H_{2}^{1} \\
& +(25,25,28) H_{3}^{1}+(25,25,28) H_{4}^{1} \\
& +(36,36,46) L_{1}^{1}+(36,36,40) L_{3}^{1}+(36,36,40) L_{2}^{1} L_{5}^{1}+(36,36,40) L_{6}^{1} \\
& +(25,28) H_{5}^{1}+(25,25,28) H_{6}^{1} \\
& +(36,45
\end{aligned}
$$




$$
\begin{aligned}
& +(19,19,21)\left(P_{r 1}^{2}+P_{o 1}^{2}\right) \\
& +(19,19,21)\left(P_{r 2}^{2}+P_{o 2}^{2}\right)+(19,19,21)\left(P_{r 3}^{2}+P_{o 3}^{2}\right) \\
& +(19,19,21)\left(P_{r 4}^{2}+P_{o 4}^{2}\right)+(20,20,22)\left(P_{r 5}^{2}+P_{o 5}^{2}\right) \\
& +(20,20,22)\left(P_{r 6}^{2}+P_{o 6}^{2}\right)+(62,62,65) W_{1}^{2} \\
& +(62,62,65) W_{2}^{2}+(64,64,68) W_{3}^{2} \\
& +(64,64,68) W_{4}^{2}+(66,66,71) W_{5}^{2} \\
& +(66,66,71) W_{6}^{2}+(16,16,18)(3.0,3.0,3.1) P_{o 1}^{2} \\
& +(16,16,18)(3.0,3.0,3.1) P_{o 2}^{2} \\
& +(17,17,19)(3.0,3.0,3.1) P_{o 3}^{2} \\
& +(17,17,19)(3.0,3.0,3.1) P_{o 4}^{2} \\
& +(18,18,20)(3.0,3.0,3.1) P_{o 5}^{2} \\
& +(18,18,20)(3.0,3.0,3.1) P_{o 6}^{2} \\
& +(1.9,1.9,2.1) I_{1}^{2}+(1.9,1.9,2.1) I_{2}^{2} \\
& +(2.0,2.0,2.2) I_{3}^{2}+(2.0,2.0,2.2) I_{4}^{2} \\
& +(2.1,2.1,2.3) I_{5}^{2}+(2.1,2.1,2.3) I_{6}^{2} \\
& +(2.7,2.7,3.0) B_{1}^{2}+(2.7,2.7,3.0) B_{2}^{2} \\
& +(2.8,2.8,3.2) B_{3}^{2}+(2.8,2.8,3.2) B_{4}^{2} \\
& +(3.1,3.1,3.4) B_{5}^{2}+(3.1,3.1,3.4) B_{6}^{2} \\
& +(26,26,28) H_{1}^{2}+(26,26,28) H_{2}^{2} \\
& +(26,26,28) H_{3}^{2}+(26,26,28) H_{4}^{2} \\
& +(26,26,28) H_{5}^{2}+(26,26,28) H_{6}^{2} \\
& +(37,37,41) L_{1}^{2}+(37,37,41) L_{2}^{2} \\
& +(37,37,41) L_{3}^{2}+(37,37,41) L_{4}^{2} \\
& +(37,37,41) L_{5}^{2}+(37,37,41) L_{6}^{2} \\
& W_{i}^{1} \leq(120,120,150), \quad i=3, \ldots, 6, \\
& W_{1}^{2} \leq(100,100,120) \text {, } \\
& W_{2}^{2} \leq(120,120,140) \text {, } \\
& W_{j}^{2} \leq(130,130,160), \quad j=3, \ldots, 6, \\
& W_{l}^{1}-W_{l-1}^{1}-H_{l}^{1}+L_{l}^{1}=0, \quad l=1, \ldots, 6 ;
\end{aligned}
$$

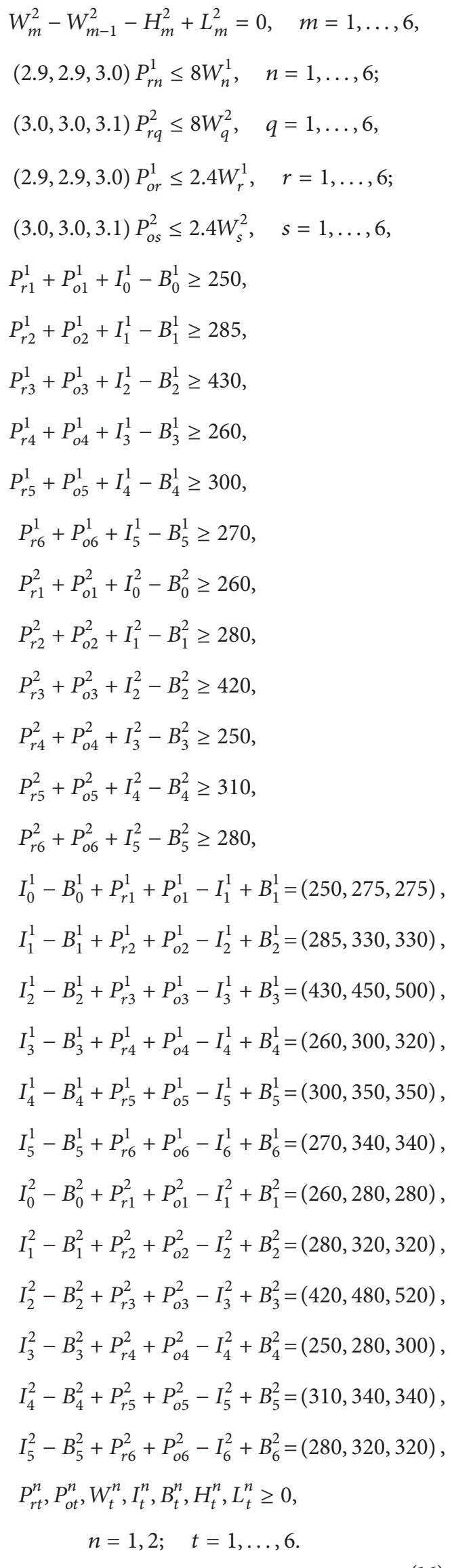


Following the solution procedure presented in Section 3, in this case, the lower and upper bounds of the minimum total $\operatorname{cost} \widetilde{Z}$ of this APP model at possibility level $\alpha$ can be obtained by solving the pair of mathematical programs according to Models (13) and (15) as follows:

$$
\begin{aligned}
Z_{\alpha}^{L}=\min . \sum_{t=1}^{6}[ & c_{p t}^{1}\left(P_{r t}^{1}+P_{o t}^{1}\right)+c_{r t}^{1} W_{t}^{1} \\
& +c_{o t}^{1}\left(k_{1}\right)\left(P_{o t}^{1}\right)+c_{i t}^{1} I_{t}^{1}+c_{b t}^{1} B_{t}^{1} \\
& +c_{h t}^{1} H_{t}^{1}+c_{l t}^{1} L_{t}^{1}+c_{p t}^{2}\left(P_{r t}^{2}+P_{o t}^{2}\right) \\
& +c_{r t}^{2} W_{t}^{2}+c_{o t}^{2}\left(k_{2}\right)\left(P_{o t}^{2}\right)+c_{i t}^{2} I_{t}^{2} \\
& \left.+c_{b t}^{2} B_{t}^{2}+c_{h t}^{2} H_{t}^{2}+c_{l t}^{2} L_{t}^{2}\right]
\end{aligned}
$$

s.t. $W_{1}^{1} \leq 100-10 \alpha, \quad W_{2}^{1} \leq 115-15 \alpha$,

$W_{i}^{1} \leq 150-30 \alpha, \quad i=3, \ldots 6$,

$W_{1}^{2} \leq 120-20 \alpha, \quad W_{2}^{2} \leq 140-20 \alpha$,

$W_{j}^{2} \leq 160-30 \alpha, \quad j=3, \ldots 6$,

$W_{l}^{1}-W_{l-1}^{1}-H_{l}^{1}+L_{l}^{1}=0, \quad l=1, \ldots, 6$;

$W_{m}^{2}-W_{m-1}^{2}-H_{m}^{2}+L_{m}^{2}=0, \quad m=1, \ldots, 6$,

$k_{1} P_{r n}^{1}-8 W_{n}^{1} \leq 0, \quad \forall n=1, \ldots, 6$;

$k_{2} P_{r q}^{2}-8 W_{q}^{2} \leq 0, \quad \forall q=1, \ldots, 6$,

$k_{1} P_{o r}^{1}-2.4 W_{r}^{1} \leq 0, \quad \forall r=1, \ldots, 6$;

$k_{2} P_{o s}^{2}-2.4 W_{s}^{2} \leq 0, \quad \forall s=1, \ldots, 6$,

$P_{r 1}^{1}+P_{o 1}^{1}+I_{0}^{1}-B_{0}^{1} \geq 250$,

$P_{r 2}^{1}+P_{o 2}^{1}+I_{1}^{1}-B_{1}^{1} \geq 285$,

$P_{r 3}^{1}+P_{o 3}^{1}+I_{2}^{1}-B_{2}^{1} \geq 430$,

$P_{r 4}^{1}+P_{o 4}^{1}+I_{3}^{1}-B_{3}^{1} \geq 260$,

$P_{r 5}^{1}+P_{o 5}^{1}+I_{4}^{1}-B_{4}^{1} \geq 300$,

$P_{r 6}^{1}+P_{o 6}^{1}+I_{5}^{1}-B_{5}^{1} \geq 270$,

$P_{r 1}^{2}+P_{o 1}^{2}+I_{0}^{2}-B_{0}^{2} \geq 260$,

$P_{r 2}^{2}+P_{o 2}^{2}+I_{1}^{2}-B_{1}^{2} \geq 280$,

$P_{r 3}^{2}+P_{o 3}^{2}+I_{2}^{2}-B_{2}^{2} \geq 420$,

$P_{r 4}^{2}+P_{o 4}^{2}+I_{3}^{2}-B_{3}^{2} \geq 250$,

$P_{r 5}^{2}+P_{o 5}^{2}+I_{4}^{2}-B_{4}^{2} \geq 310$,

$P_{r 6}^{2}+P_{o 6}^{2}+I_{5}^{2}-B_{5}^{2} \geq 280$,

$$
\begin{aligned}
& I_{0}^{1}-B_{0}^{1}+P_{r 1}^{1}+P_{o 1}^{1}-I_{1}^{1}+B_{1}^{1}=f_{1}^{1}, \\
& I_{1}^{1}-B_{1}^{1}+P_{r 2}^{1}+P_{o 2}^{1}-I_{2}^{1}+B_{2}^{1}=f_{2}^{1}, \\
& I_{2}^{1}-B_{2}^{1}+P_{r 3}^{1}+P_{o 3}^{1}-I_{3}^{1}+B_{3}^{1}=f_{3}^{1}, \\
& I_{3}^{1}-B_{3}^{1}+P_{r 4}^{1}+P_{o 4}^{1}-I_{4}^{1}+B_{4}^{1}=f_{4}^{1}, \\
& I_{4}^{1}-B_{4}^{1}+P_{r 5}^{1}+P_{o 5}^{1}-I_{5}^{1}+B_{5}^{1}=f_{5}^{1}, \\
& I_{5}^{1}-B_{5}^{1}+P_{r 6}^{1}+P_{o 6}^{1}-I_{6}^{1}+B_{6}^{1}=f_{6}^{1} \text {, } \\
& I_{0}^{2}-B_{0}^{2}+P_{r 1}^{2}+P_{o 1}^{2}-I_{1}^{2}+B_{1}^{2}=f_{1}^{2}, \\
& I_{1}^{2}-B_{1}^{2}+P_{r 2}^{2}+P_{o 2}^{2}-I_{2}^{2}+B_{2}^{2}=f_{2}^{2}, \\
& I_{2}^{2}-B_{2}^{2}+P_{r 3}^{2}+P_{o 3}^{2}-I_{3}^{2}+B_{3}^{2}=f_{3}^{2}, \\
& I_{3}^{2}-B_{3}^{2}+P_{r 4}^{2}+P_{o 4}^{2}-I_{4}^{2}+B_{4}^{2}=f_{4}^{2}, \\
& I_{4}^{2}-B_{4}^{2}+P_{r 5}^{2}+P_{o 5}^{2}-I_{5}^{2}+B_{5}^{2}=f_{5}^{2}, \\
& I_{5}^{2}-B_{5}^{2}+P_{r 6}^{2}+P_{o 6}^{2}-I_{6}^{2}+B_{6}^{2}=f_{6}^{2}, \\
& 250+25 \alpha \leq f_{1}^{1} \leq 275, \\
& 285+45 \alpha \leq f_{2}^{1} \leq 330, \\
& 430+20 \alpha \leq f_{3}^{1} \leq 500-50 \alpha, \\
& 260+40 \alpha \geq f_{4}^{1} \leq 320-20 \alpha, \\
& 300 \leq f_{5}^{1} \leq 350-50 \alpha, \\
& 270 \leq f_{6}^{1} \leq 340-70 \alpha, \\
& 260+20 \alpha \leq f_{1}^{2} \leq 280, \\
& 280+40 \alpha \leq f_{2}^{2} \leq 320, \\
& 420+60 \alpha \leq f_{3}^{2} \leq 520-40 \alpha, \\
& 250+30 \alpha \leq f_{4}^{2} \leq 300-20 \alpha, \\
& 310 \leq f_{5}^{2} \leq 340-30 \alpha, \\
& 280 \leq f_{6}^{2} \leq 320-40 \alpha, \\
& 18 \leq c_{p t}^{1} \leq 20-2 \alpha, \quad t=1,2 ; \\
& 19 \leq c_{p t}^{1} \leq 21-2 \alpha, \quad t=3,4, \\
& 20 \leq c_{p t}^{1} \leq 22-2 \alpha, \quad t=5,6 ; \\
& 19 \leq c_{p t}^{2} \leq 21-2 \alpha, \quad t=1,2, \\
& 20 \leq c_{p t}^{2} \leq 22-2 \alpha, \quad t=3,4 ; \\
& 21 \leq c_{p t}^{2} \leq 23-2 \alpha, \quad t=5,6,
\end{aligned}
$$




$$
\begin{aligned}
& 15 \leq c_{o t}^{1} \leq 17-2 \alpha, \quad t=1,2 ; \\
& 16 \leq c_{o t}^{1} \leq 18-2 \alpha, \quad t=3,4, \\
& 17 \leq c_{o t}^{1} \leq 19-2 \alpha, \quad t=5,6 ; \\
& 16 \leq c_{o t}^{2} \leq 18-2 \alpha, \quad t=1,2, \\
& 17 \leq c_{o t}^{2} \leq 19-2 \alpha, \quad t=3,4 ; \\
& 18 \leq c_{o t}^{2} \leq 20-2 \alpha, \quad t=5,6, \\
& 60 \leq c_{r t}^{1} \leq 64-4 \alpha, \quad t=1,2 ; \\
& 62 \leq c_{r t}^{1} \leq 65-3 \alpha, \quad t=3,4, \\
& 64 \leq c_{r t}^{1} \leq 69-5 \alpha, \quad t=5,6 ; \\
& 62 \leq c_{r t}^{2} \leq 65-3 \alpha, \quad t=1,2, \\
& 64 \leq c_{r t}^{2} \leq 68-4 \alpha, \quad t=3,4 ; \\
& 66 \leq c_{r t}^{2} \leq 71-5 \alpha, \quad t=5,6, \\
& 1.8 \leq c_{i t}^{1} \leq 2.0-0.2 \alpha, \quad t=1,2 ; \\
& 1.9 \leq c_{i t}^{1} \leq 2.1-0.2 \alpha, \quad t=3,4 \text {, } \\
& 2.0 \leq c_{i t}^{1} \leq 2.2-0.2 \alpha, \quad t=5,6 ; \\
& 1.9 \leq c_{i t}^{2} \leq 2.1-0.2 \alpha, \quad t=1,2, \\
& 2.0 \leq c_{i t}^{2} \leq 2.2-0.2 \alpha, \quad t=3,4 ; \\
& 2.0 \leq c_{i t}^{2} \leq 2.2-0.2 \alpha, \quad t=5,6, \\
& 2.5 \leq c_{b t}^{1} \leq 2.7-0.2 \alpha, \quad t=1,2 ; \\
& 2.7 \leq c_{b t}^{1} \leq 3.0-0.3 \alpha, \quad t=3,4, \\
& 2.9 \leq c_{b t}^{1} \leq 3.1-0.2 \alpha, \quad t=5,6 ; \\
& 2.7 \leq c_{b t}^{2} \leq 3.0-0.3 \alpha, \quad t=1,2, \\
& 2.8 \leq c_{b t}^{2} \leq 3.2-0.4 \alpha, \quad t=3,4 ; \\
& 3.1 \leq c_{b t}^{2} \leq 3.4-0.3 \alpha, \quad t=5,6, \\
& 25 \leq c_{h t}^{1} \leq 28-3 \alpha, \quad 26 \leq c_{h t}^{2} \leq 28-2 \alpha, \\
& 36 \leq c_{l t}^{1} \leq 40-4 \alpha, \quad 37 \leq c_{l t}^{2} \leq 41-4 \alpha, \\
& 2.9 \leq k_{1} \leq 3.0-0.1 \alpha, \\
& 3.0 \leq k_{2} \leq 3.1-0.1 \alpha \text {, } \\
& P_{r t}^{n}, P_{o t}^{n}, W_{t}^{n}, I_{t}^{n}, B_{t}^{n}, H_{t}^{n}, L_{t}^{n} \geq 0, \\
& n=1,2 ; \quad t=1, \ldots, 6 \text {. } \\
& \begin{aligned}
Z_{\alpha}^{U}=\max . & -\left(90 A_{1}^{1}+100 A_{2}^{1}+\sum_{t=3}^{6} 120 A_{t}^{1}\right)-100 N_{1}^{1} \\
& +250 G_{1}^{1}+285 G_{2}^{1}+430 G_{3}^{1}+260 G_{4}^{1} \\
& +300 G_{5}^{1}+270 G_{6}^{1}+\sum_{t=1}^{6} f_{t}^{1} M_{t}^{1} \\
& -\left(100 A_{1}^{2}+120 A_{2}^{2}+\sum_{t=3}^{6} 130 A_{t}^{2}\right)-150 N_{1}^{2} \\
& +260 G_{1}^{2}+280 G_{2}^{2}+420 G_{3}^{2}+250 G_{4}^{2} \\
& +310 G_{5}^{2}+280 G_{6}^{2}+\sum_{t=1}^{6} f_{t}^{2} M_{t}^{2}
\end{aligned} \\
& \text { s.t. } \quad-k_{1} D_{t}^{1}+G_{t}^{1}+M_{t}^{1} \leq c_{p t}^{1}, \quad t=1,2, \ldots, 6 \\
& -k_{2} D_{t}^{2}+G_{t}^{2}+M_{t}^{2} \leq c_{p t}^{2}, \quad t=1,2, \ldots, 6 \\
& -k_{1} E_{t}^{1}+G_{t}^{1}+M_{t}^{1} \leq c_{p t}^{1}+k_{1} c_{o t}^{1} \\
& t=1,2, \ldots, 6 \\
& -k_{2} E_{t}^{2}+G_{t}^{2}+M_{t}^{2} \leq c_{p t}^{2}+k_{2} c_{o t}^{2} \\
& t=1,2, \ldots, 6 \\
& -A_{t}^{1}-N_{t}^{1}+B_{t+1}^{1}+8 D_{t}^{1}+2.4 E_{t}^{1} \leq c_{r t}^{1} \text {, } \\
& t=1,2, \ldots, 5 \\
& -A_{t}^{2}-N_{t}^{2}+B_{t+1}^{2}+8 D_{t}^{2}+2.4 E_{t}^{2} \leq c_{r t}^{2} \text {, } \\
& t=1,2, \ldots, 5 \\
& -A_{6}^{1}-C_{6}^{1}+8 D_{6}^{1}+2.4 E_{6}^{1} \leq c_{r 6}^{1} \text {, } \\
& -A_{6}^{2}-C_{6}^{2}+8 D_{6}^{2}+2.4 E_{6}^{2} \leq c_{r 6}^{2} \text {, } \\
& G_{t+1}^{1}-M_{t}^{1}+H_{t+1}^{1} \leq c_{i t}^{1}, \quad t=1,2, \ldots, 5 \\
& G_{t+1}^{2}-M_{t}^{2}+H_{t+1}^{2} \leq c_{i t}^{2}, \quad t=1,2, \ldots, 5 \\
& -M_{6}^{1} \leq c_{i 6}^{1}, \quad-M_{6}^{2} \leq c_{i 6}^{2}, \\
& -G_{t+1}^{1}+M_{t}^{1}-M_{t+1}^{1} \leq c_{b t}^{1}, \quad t=1,2, \ldots, 5 \\
& -G_{t+1}^{2}+M_{t}^{2}-M_{t+1}^{2} \leq c_{b t}^{2}, \quad t=1,2, \ldots, 5 \\
& M_{6}^{1} \leq c_{b 6}^{1}, \quad M_{6}^{2} \leq c_{b 6}^{2}, \\
& N_{t}^{1} \leq c_{h t}^{1}, \quad t=1,2, \ldots, 6 \\
& N_{t}^{2} \leq c_{h t}^{2}, \quad t=1,2, \ldots, 6 \\
& -N_{t}^{1} \leq c_{l t}^{1}, \quad t=1,2, \ldots, 6 \\
& -N_{t}^{2} \leq c_{l t}^{2}, \quad t=1,2, \ldots, 6
\end{aligned}
$$




$$
\begin{aligned}
& 250+25 \alpha \leq f_{1}^{1} \leq 275 \\
& 285+45 \alpha \leq f_{2}^{1} \leq 330 \\
& 430+20 \alpha \leq f_{3}^{1} \leq 500-50 \alpha \\
& 260+40 \alpha \leq f_{4}^{1} \leq 320-20 \alpha \\
& 300 \leq f_{5}^{1} \leq 350-50 \alpha \\
& 270 \leq f_{6}^{1} \leq 340-70 \alpha \\
& 220+25 \alpha \leq f_{1}^{2} \leq 275 \\
& 305+45 \alpha \leq f_{2}^{2} \leq 350 \\
& 400+20 \alpha \leq f_{3}^{2} \leq 470-50 \alpha \\
& 260+40 \alpha \leq f_{4}^{2} \leq 320-20 \alpha \\
& 300 \leq f_{5}^{2} \leq 350-50 \alpha \\
& 270 \leq f_{6}^{2} \leq 340-70 \alpha \\
& 18+2 \alpha \leq c_{p t}^{1} \leq 22-2 \alpha, \quad \forall t \\
& 19+2 \alpha \leq c_{p t}^{2} \leq 23-2 \alpha, \quad \forall t \\
& 60+5 \alpha \leq c_{o t}^{1} \leq 70-5 \alpha, \quad \forall t \\
& 50+5 \alpha \leq c_{o t}^{2} \leq 60-5 \alpha, \quad \forall t \\
& 60+4 \alpha \leq c_{r t}^{1} \leq 68-4 \alpha, \quad \forall t \\
& 62+4 \alpha \leq c_{r t}^{2} \leq 70-4 \alpha, \quad \forall t \\
& 1.8+0.2 \alpha \leq c_{i t}^{1} \leq 2.2-0.2 \alpha, \quad \forall t \\
& 1.9+0.2 \alpha \leq c_{i t}^{2} \leq 2.3-0.2 \alpha, \quad \forall t \\
& 2.5+0.5 \alpha \leq c_{b t}^{1} \leq 3.5-0.5 \alpha, \quad \forall t \\
& 2.8+0.5 \alpha \leq c_{b t}^{2} \leq 3.8-0.5 \alpha, \quad \forall t \\
& 25+5 \alpha \leq c_{h t}^{1} \leq 35-5 \alpha, \quad \forall t \\
& 25+5 \alpha \leq c_{h t}^{2} \leq 35-5 \alpha, \quad \forall t \\
& 36+4 \alpha \leq c_{l t}^{1} \leq 44-4 \alpha, \quad \forall t \\
& 36+5 \alpha \leq c_{l t}^{2} \leq 44-4 \alpha, \quad \forall t \\
& 2.9+0.1 \alpha \leq k_{t}^{1} \leq 3.1-0.1 \alpha, \quad \forall t \\
& 2.9+0.1 \alpha \leq k_{t}^{2} \leq 3.1-0.1 \alpha, \quad \forall t \\
& P_{r t}^{n}, P_{o t}^{n}, W_{t}^{n}, I_{t}^{n}, B_{t}^{n}, H_{t}^{n}, L_{t}^{n} \geq 0, \\
& n=1,2 ; \quad t=1, \ldots, 6 \text {. }
\end{aligned}
$$

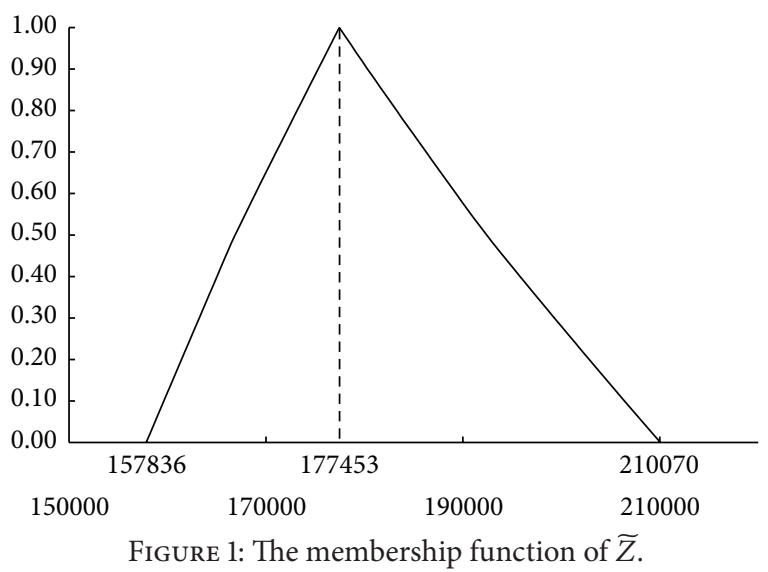

The mathematical programming solver Lingo [49] was used to solve these problems. Table 9 lists the $\alpha$-cuts of the minimum total cost for 11 distinct values of $\alpha$, and its approximated membership function is shown in Figure 1.

\section{Discussion}

The fuzziness of the input data in the APP causes the minimum total cost to be fuzzy as well. The possibility with which the total cost of the APP will appear in the associated range is represented by the $\alpha$-cut of $\widetilde{Z}$, where one extreme $(\alpha=1)$ displays the most probable total cost and the other extreme $(\alpha=0)$ displays the range in which the total cost might appear. The minimum total cost for the example discussed in this paper is most likely 177,453 ; it will never exceed 210,070 or fall below 157,836 . It is important to note that the approximate shape of the obtained membership function shown in Figure 1 appears to be rather fine and resembles a continuous function. It is also important to note that even if all of the fuzzy input parameters are triangular fuzzy numbers, the associated membership function of the performance measure is nonlinear, although it appears triangular.

Using the proposed solution procedure, the optimal operation plans can be obtained simultaneously and are related to the lower or upper bounds of the minimum total cost at these 11 values of $\alpha$ which are given in Table 10. It was shown that for any $\alpha$, we obtain $H_{t}^{n} L_{t}^{n}=0$ and $I_{t}^{n} B_{t}^{n}=0, \forall n, t$, which confirms the optimality of the operation plans as generated by the approach proposed in this work and that it is unnecessary to enforce these two sets of constraints on the APP model. The obtained results for the lower bounds of the minimum total cost reveal that the productivity of the production plan increases with the use of overtime production, the hiring of fewer workers, and the establishment of a lower inventory level to meet the forecasted demands without exceeding the resources needed for a higher $\alpha$ level. However, to optimise the operation plan if a lower $\alpha$ level is presented, the decision maker should hire additional workers to produce additional output using regular-time production and built-up inventory.

5.1. Comparison. The parametric programming approach proposed by Chanas [50] and Chanas and Kulej [51] (also 
TABLE 9: The $\alpha$-cuts of minimum total cost at $11 \alpha$ values.

\begin{tabular}{cccccccccccc}
\hline$\alpha$ & 0.0 & 0.1 & 0.2 & 0.3 & 0.4 & 0.5 & 0.6 & 0.7 & 0.8 & 0.9 & 1.0 \\
\hline$Z_{\alpha}^{L}$ & 157836 & 159631 & 161425 & 163225 & 165026 & 166866 & 168932 & 171040 & 173167 & 175305 & 177453 \\
$Z_{\alpha}^{U}$ & 210070 & 206415 & 202835 & 199300 & 195811 & 192423 & 189292 & 186269 & 183275 & 180303 & 177453 \\
\hline
\end{tabular}

referred to as Chanas' approach) was used by Lai and Hwang [30] to solve the APP problem. Their efforts generated solutions for 11 values of $\alpha$, namely, $0.0,0.1, \ldots, 1.0$. The minimum total cost reported in Lai and Hwang [30] was a crisp number rather than an interval, and each value of $\alpha$ corresponds to the lower bound obtained from the proposed approach (refer to the second row of Table 9).

Similar to Chanas' approach, the approach proposed in this paper is based on FLP, yet the two are significantly different in both methodology and obtained results. The proposed approach is based on a combination of Zadeh's extension principle, the LP formation of the APP problem, $\alpha$-cut representation, two-level mathematical programming, and parametric programming; therefore, we were able to generate results that have completely conserved the fuzziness of the 10 sets of parameters, while Chanas' approach merely showed a crisp minimum total cost for the different probability levels and the corresponding values of decision variables with fuzzy resource right-hand-side constraints (i.e., workforce levels and demands) [30]. Therefore, in contrast to Chanas' approach, this paper has been able to more realistically represent the fuzzy sets by maintaining the fuzziness of the parameters, including the objective function coefficients (i.e., unit production cost excluding labour cost, overtime labour cost, labour cost, inventory carrying cost, cost to hire one worker, cost to lay off one worker, and unit backorder cost), technical coefficients (i.e., conversion factor in hours of labour), and resource right-hand-side constraints (i.e., forecasted demands and maximum workforce). Consequently, compared with Chanas' approach, it is clear that the proposed approach has a wider potential for application to different types of APP problems and that the obtained results are more realistic.

5.2. Practical Viewpoint. Because the optimal production plans of this numerical application are described by fuzzy sets (refer to Tables 9 and 10), they conserve all of the fuzziness of input information. From the practical point of view, the management could prefer the optimal production plans with crisp values rather than fuzzy values. In this paper a more representative defuzzification method, called the graded mean integration (GMI) representation, is adopted to transform the resulting fuzzy minimum total cost and the fuzzy values of decision values into crisp values. Consider a fuzzy number $\widetilde{A}$ with the membership function $\mu_{\widetilde{A}}(x)$, the left-shape function $L(x)$, and the right-shape function $R(x)$. Let $L^{-1}(\alpha)$ and $R^{-1}(\alpha)$ be the inverse functions of $L(x)$ and $R(x)$, respectively. The GMI representation of $\widetilde{A}$ is defined as

$$
\operatorname{GMI}(\widetilde{A})=\frac{\int_{0}^{1} 0.5 \alpha\left[L^{-1}(\alpha)+R^{-1}(\alpha)\right] d \alpha}{\int_{0}^{1} \alpha d \alpha}
$$

The GMI method has been demonstrated to be more representative than several methods proposed by previous studies [52].

\section{Conclusion}

Throughout the last few decades, fuzzy APP problems have fascinated many researchers, leading to the creation of a range of models. This paper proposes a parametric programming approach based primarily on the concept of $\alpha$-cuts and Zadeh's extension principle. The fuzzy APP model is transformed into a family of crisp APP models that are described by a pair of mathematical programs. This approach allows the users to derive the membership function of the fuzzy minimum total costs of the APP problem associated with the fuzzy parameters. The lower and upper bounds of the $\alpha$-cuts of the fuzzy minimum total cost are calculated for each of the different possibility levels $\alpha$, after which the membership function can be approximated such that the correlated optimal APPs can be determined.

It has also become clear that a linguistic presentation is practical and more suitable for representing the imprecise parameters in the APP. When the results obtained are crisp values, managers could ignore the loss of fuzziness from input information, thereby stimulating management based upon overly optimistic decisions. In contrast, we demonstrated that our proposed approach is able to completely conserve the fuzziness that was associated with the ambiguous APP data, particularly by expressing the objective value with membership functions rather than crisp values. Thus, the proposed approach is able to generate more reasonable solutions for imprecise or fuzzy parameters compared to other studies, offering the decision maker information that other approaches cannot. Consequently, the decision makers can generate a feasible disaggregate plan based on alternative strategies that address fuzzy or imprecise parameters (e.g., overtime, inventory, backorder, and hiring and laying off of workers). The APP models based upon different structures (e.g., multisite, multiobjectives, multiple goal priorities, resource utilisation constraints, and aggregate production-distribution planning in SCM) are also eligible for the approach proposed in this paper. Future research will consider the development of multiobjective decision methods.

\section{Conflict of Interests}

The authors declare that there is no conflict of interests regarding the publication of this paper. 
TABLE 10: Optimal aggregate production plans corresponding to lower and up per (in parentheses) bounds at $11 \alpha$ values.

\begin{tabular}{|c|c|c|c|c|c|c|c|c|c|c|c|}
\hline$\alpha$ & 0.0 & 0.1 & 0.2 & 0.3 & 0.4 & 0.5 & 0.6 & 0.7 & 0.8 & 0.9 & 1.0 \\
\hline$P_{r 1}^{1}$ & $276(240)$ & $274(241)$ & $270(242)$ & $268(242)$ & $265(243)$ & $262(244)$ & $259(245)$ & 257 (246) & 254 (247) & $251(247)$ & $248(248)$ \\
\hline$P_{r 2}^{1}$ & $318(267)$ & $313(268)$ & 309 (269) & 305 (269) & $301(270)$ & $297(271)$ & $292(272)$ & $288(273)$ & $284(274)$ & $280(275)$ & $276(276)$ \\
\hline$P_{r 3}^{1}$ & $318(320)$ & $313(321)$ & 309 (322) & $322(323)$ & 337 (324) & $352(325)$ & $362(327)$ & $356(328)$ & 348 (329) & $339(330)$ & $331(331)$ \\
\hline$P_{r 4}^{1}$ & $280(320)$ & $283(321)$ & $286(322)$ & $289(323)$ & $292(324)$ & $295(325)$ & $298(327)$ & $302(328)$ & 308 (329) & $314(327)$ & $320(320)$ \\
\hline$P_{r 5}^{1}$ & $280(320)$ & $283(321)$ & $286(322)$ & $289(323)$ & $292(324)$ & $295(325)$ & $298(321)$ & $300(323)$ & $300(305)$ & $300(300)$ & $300(300)$ \\
\hline$P_{r 6}^{1}$ & $270(320)$ & $270(315)$ & $270(310)$ & $270(305)$ & $270(300)$ & $270(295)$ & $270(290)$ & $270(285)$ & $270(280)$ & $270(275)$ & $270(270)$ \\
\hline$P_{r 1}^{2}$ & $320(259)$ & 315 (259) & $309(260)$ & $304(261)$ & $299(261)$ & $293(262)$ & $288(263)$ & $283(264)$ & $277(265)$ & $272(266)$ & $267(267)$ \\
\hline$P_{r 2}^{2}$ & $320(310)$ & $326(311)$ & $331(312)$ & 337 (313) & $343(314)$ & 347 (315) & $341(316)$ & $336(317)$ & $331(318)$ & 325 (319) & $320(320)$ \\
\hline$P_{r 3}^{2}$ & $320(336)$ & $326(337)$ & $331(338)$ & 337 (339) & $343(340)$ & $350(341)$ & $367(342)$ & $371(343)$ & $363(344)$ & $355(346)$ & 347 (347) \\
\hline$P_{r 4}^{2}$ & $280(336)$ & 285 (337) & $289(338)$ & 294 (339) & $298(340)$ & 303 (341) & $307(342)$ & $313(343)$ & $322(344)$ & $331(346)$ & $340(340)$ \\
\hline$P_{r 5}^{2}$ & $280(336)$ & $285(337)$ & $289(338)$ & 294 (339) & $298(340)$ & 303 (339) & 307 (332) & $310(325)$ & $310(318)$ & $310(310)$ & $310(310)$ \\
\hline$P_{r 6}^{2}$ & $280(210)$ & $280(307)$ & $280(304)$ & $280(301)$ & $280(298)$ & $280(295)$ & $280(292)$ & $280(289)$ & $280(286)$ & $280(283)$ & $280(280)$ \\
\hline$P_{o 1}^{1}$ & $0(72)$ & $0(72)$ & $0(72)$ & $0(73)$ & $0(73)$ & $0(73)$ & $6(73)$ & $27(73)$ & $50(74)$ & $74(74)$ & $75(75)$ \\
\hline$P_{o 2}^{1}$ & $55(80)$ & $73(80)$ & $91(81)$ & $91(91)$ & $90(81)$ & $89(81)$ & $88(82)$ & $86(82)$ & $85(82)$ & $84(82)$ & $83(83)$ \\
\hline$P_{o 3}^{1}$ & $0(96)$ & $0(94)$ & $0(81)$ & $0(69)$ & $0(56)$ & $0(44)$ & $0(36)$ & $0(33)$ & $0(30)$ & $0(26)$ & $23(23)$ \\
\hline$P_{o 4}^{1}$ & $0(10)$ & $0(0)$ & $0(0)$ & $0(0)$ & $0(0)$ & $0(0)$ & $0(0)$ & $0(0)$ & $0(0)$ & $0(0)$ & $0(0)$ \\
\hline$P_{o 5}^{1}$ & $0(0)$ & $0(0)$ & $0(0)$ & $0(0)$ & $0(0)$ & $0(0)$ & $0(0)$ & $0(0)$ & $0(0)$ & $0(0)$ & $0(0)$ \\
\hline$P_{o 6}^{1}$ & $0(0)$ & $0(0)$ & $0(0)$ & $0(0)$ & $0(0)$ & $0(0)$ & $0(0)$ & $0(0)$ & $0(0)$ & $0(0)$ & $0(0)$ \\
\hline$P_{o 1}^{2}$ & $0(22)$ & $0(21)$ & $0(20)$ & 0 (19) & 0 (19) & $0(18)$ & 0 (17) & $0(16)$ & $0(15)$ & $6(14)$ & $13(13)$ \\
\hline$P_{o 2}^{2}$ & 0 (93) & $0(93)$ & $0(94)$ & $0(94)$ & $0(93)$ & $0(84)$ & $0(82)$ & $13(80)$ & $37(78)$ & $56(75)$ & $73(73)$ \\
\hline$P_{03}^{2}$ & $0(41)$ & $0(30)$ & $0(20)$ & $0(9)$ & $0(0)$ & $0(0)$ & $0(0)$ & $0(0)$ & $0(0)$ & $0(0)$ & $0(0)$ \\
\hline$P_{o 4}^{2}$ & $0(0)$ & $0(0)$ & $0(0)$ & $0(0)$ & $0(0)$ & $0(0)$ & $0(0)$ & $0(0)$ & $0(0)$ & $0(0)$ & $0(0)$ \\
\hline$P_{05}^{2}$ & $0(0)$ & $0(0)$ & $0(0)$ & $0(0)$ & $0(0)$ & $0(0)$ & $0(0)$ & $0(0)$ & $0(0)$ & $0(0)$ & $0(0)$ \\
\hline$P_{o 6}^{2}$ & $0(0)$ & $0(0)$ & $0(0)$ & $0(0)$ & $0(0)$ & $0(0)$ & $0(0)$ & $0(0)$ & $0(0)$ & $0(0)$ & $0(0)$ \\
\hline$I_{1}^{1}$ & $26(37)$ & $21(38)$ & $15(39)$ & $10(40)$ & $5(41)$ & $0(42)$ & $0(43)$ & $16(45)$ & $34(46)$ & $52(47)$ & $48(48)$ \\
\hline$I_{2}^{1}$ & $113(54)$ & $117(56)$ & $121(58)$ & $108(60)$ & $93(63)$ & $78(65)$ & $68(67)$ & $74(69)$ & $82(72)$ & $91(74)$ & $76(76)$ \\
\hline$I_{3}^{1}$ & $0(0)$ & $0(0)$ & $0(0)$ & $0(0)$ & $0(0)$ & $0(0)$ & $0(0)$ & $0(0)$ & $0(0)$ & $0(0)$ & $0(0)$ \\
\hline$I_{4}^{1}$ & $20(0)$ & $17(0)$ & $14(0)$ & $11(0)$ & $8(0)$ & $5(0)$ & $2(0)$ & $0(0)$ & $0(0)$ & $0(0)$ & $0(0)$ \\
\hline$I_{5}^{1}$ & $0(0)$ & $0(0)$ & $0(0)$ & $0(0)$ & $0(0)$ & $0(0)$ & $0(0)$ & $0(0)$ & $0(0)$ & $0(0)$ & $0(0)$ \\
\hline$I_{6}^{1}$ & $0(0)$ & $0(0)$ & $0(0)$ & $0(0)$ & $0(0)$ & $0(0)$ & $0(0)$ & $0(0)$ & $0(0)$ & $0(0)$ & $0(0)$ \\
\hline$I_{1}^{2}$ & $60(0)$ & $53(0)$ & $45(0)$ & $38(0)$ & $31(0)$ & $23(0)$ & $16(0)$ & $9(0)$ & $1(0)$ & $0(0)$ & $0(0)$ \\
\hline$I_{2}^{2}$ & $100(83)$ & $94(84)$ & $89(85)$ & $83(87)$ & $77(86)$ & $70(79)$ & $53(78)$ & $49(77)$ & $57(76)$ & $65(74)$ & $73(73)$ \\
\hline$I_{3}^{3}$ & $0(0)$ & $0(0)$ & $0(0)$ & $0(0)$ & $0(0)$ & $0(0)$ & $0(0)$ & $0(0)$ & $0(0)$ & $0(0)$ & $0(0)$ \\
\hline$I_{4}^{4}$ & $30(0)$ & $26(0)$ & $21(0)$ & $17(0)$ & $12(0)$ & $8(0)$ & $3(0)$ & $0(0)$ & $0(0)$ & $0(0)$ & $0(0)$ \\
\hline$I_{5}^{5}$ & $0(0)$ & $0(0)$ & $0(0)$ & $0(0)$ & $0(0)$ & $0(0)$ & $0(0)$ & $0(0)$ & $0(0)$ & $0(0)$ & $0(0)$ \\
\hline$I_{6}^{6}$ & $0(0)$ & $0(0)$ & $0(0)$ & $0(0)$ & $0(0)$ & $0(0)$ & $0(0)$ & $0(0)$ & $0(0)$ & $0(0)$ & $0(0)$ \\
\hline$B_{1}^{1}$ & $0(0)$ & $0(0)$ & $0(0)$ & $0(0)$ & $0(0)$ & $0(0)$ & $0(0)$ & $0(0)$ & $0(0)$ & $0(0)$ & $0(0)$ \\
\hline$B_{2}^{1}$ & $0(0)$ & $0(0)$ & $0(0)$ & $0(0)$ & $0(0)$ & $0(0)$ & $0(0)$ & $0(0)$ & $0(0)$ & $0(0)$ & $0(0)$ \\
\hline$B_{3}^{1}$ & $0(30)$ & $2(24)$ & $4(28)$ & $6(32)$ & $8(37)$ & $10(41)$ & $12(40)$ & $14(35)$ & $16(30)$ & $18(25)$ & $20(20)$ \\
\hline$B_{4}^{1}$ & $0(20)$ & $0(21)$ & $0(22)$ & $0(23)$ & $0(24)$ & $0(25)$ & $0(22)$ & $0(13)$ & $0(5)$ & $0(0)$ & $0(0)$ \\
\hline$B_{5}^{1}$ & $0(50)$ & $0(45)$ & $0(40)$ & $0(35)$ & $0(30)$ & $0(25)$ & $0(20)$ & $0(15)$ & $0(10)$ & $0(5)$ & $0(0)$ \\
\hline$B_{6}^{1}$ & $0(70)$ & $0(63)$ & $0(56)$ & $0(49)$ & $0(42)$ & $0(35)$ & $0(28)$ & $0(21)$ & $0(14)$ & $0(0)$ & $0(0)$ \\
\hline$B_{1}^{2}$ & $0(0)$ & $0(0)$ & $0(0)$ & $0(0)$ & $0(0)$ & $0(0)$ & $0(0)$ & $0(0)$ & $0(0)$ & $0(0)$ & $0(0)$ \\
\hline$B_{2}^{2}$ & $0(0)$ & $0(0)$ & $0(0)$ & $0(0)$ & $0(0)$ & $0(0)$ & $0(0)$ & $0(0)$ & $0(0)$ & $0(0)$ & $0(0)$ \\
\hline$B_{3}^{2}$ & $0(61)$ & $6(65)$ & $12(69)$ & $18(74)$ & $24(78)$ & $30(80)$ & $36(76)$ & $42(72)$ & $48(68)$ & $54(64)$ & $60(60)$ \\
\hline$B_{4}^{2}$ & $0(26)$ & $0(27)$ & $0(28)$ & $0(29)$ & $0(30)$ & $0(29)$ & $0(22)$ & $0(14)$ & $0(8)$ & $0(0)$ & $0(0)$ \\
\hline$B_{5}^{2}$ & $0(30)$ & $0(27)$ & $0(24)$ & $0(21)$ & $0(18)$ & $0(15)$ & $0(12)$ & $0(9)$ & $0(6)$ & $0(3)$ & $0(0)$ \\
\hline$B_{6}^{2}$ & $0(40)$ & $0(35)$ & $0(32)$ & $0(28)$ & $0(24)$ & $0(20)$ & $0(16)$ & $0(12)$ & $0(8)$ & $0(4)$ & $0(0)$ \\
\hline$W_{1}^{1}$ & $100(90)$ & $99(90)$ & $98(90)$ & $97(90)$ & $96(90)$ & $95(90)$ & $94(90)$ & $93(90)$ & $92(90)$ & $91(90)$ & $90(90)$ \\
\hline$W_{2}^{1}$ & $100(100)$ & $114(100)$ & $112(100)$ & $111(100)$ & $109(100)$ & $108(100)$ & $106(100)$ & $105(100)$ & $103(100)$ & $102(100)$ & $100(100)$ \\
\hline$W_{3}^{1}$ & $115(120)$ & $104(120)$ & $112(120)$ & $117(120)$ & $122(120)$ & $128(120)$ & $131(120)$ & $129(120)$ & $126(120)$ & $123(120)$ & $120(120)$ \\
\hline
\end{tabular}


TABle 10: Continued.

\begin{tabular}{|c|c|c|c|c|c|c|c|c|c|c|c|}
\hline$\alpha$ & 0.0 & 0.1 & 0.2 & 0.3 & 0.4 & 0.5 & 0.6 & 0.7 & 0.8 & 0.9 & 1.0 \\
\hline$W_{4}^{1}$ & $102(120)$ & $103(120)$ & $104(120)$ & $105(120)$ & $106(120)$ & $107(120)$ & $108(120)$ & 109 (120) & $112(120)$ & 114 (119) & 116 (116) \\
\hline$W_{5}^{1}$ & $102(120)$ & $103(120)$ & $104(120)$ & $105(120)$ & $106(120)$ & $107(120)$ & 108 (118) & 109 (115) & 109 (111) & 109 (109) & 109 (109) \\
\hline$W_{6}^{1}$ & $98(120)$ & 98 (118) & 98 (115) & 98 (113) & 98 (111) & 98 (109) & 98 (107) & 98 (104) & $98(102)$ & $98(100)$ & $98(98)$ \\
\hline$W_{1}^{2}$ & $120(100)$ & $118(100)$ & $116(100)$ & $114(100)$ & $112(100)$ & $110(100)$ & $108(100)$ & $106(100)$ & $104(100)$ & $102(100)$ & $100(100)$ \\
\hline$W_{2}^{2}$ & $120(120)$ & $122(120)$ & $124(120)$ & $126(120)$ & $129(120)$ & $130(120)$ & $128(120)$ & $126(120)$ & $124(120)$ & $122(120)$ & $120(120)$ \\
\hline$W_{3}^{2}$ & $120(130)$ & $122(130)$ & $124(130)$ & $126(130)$ & $129(130)$ & $131(130)$ & $138(130)$ & $139(130)$ & $136(130)$ & $133(130)$ & $130(130)$ \\
\hline$W_{4}^{2}$ & $105(130)$ & $107(130)$ & $108(130)$ & $110(130)$ & $112(130)$ & $113(130)$ & 115 (130) & 117 (130) & $121(130)$ & $124(130)$ & 128 (128) \\
\hline$W_{5}^{2}$ & $105(130)$ & 107 (130) & $108(130)$ & $110(130)$ & $112(130)$ & 113 (129) & 115 (126) & $116(123)$ & $116(120)$ & 116 (117) & $116(116)$ \\
\hline$W_{6}^{2}$ & 105 (120) & 105 (119) & 105 (117) & 105 (116) & 105 (114) & 105 (112) & 105 (111) & 105 (109) & 105 (108) & 105 (106) & 105 (105) \\
\hline$H_{1}^{1}$ & $0(0)$ & $0(0)$ & $0(0)$ & $0(0)$ & $0(0)$ & $0(0)$ & $0(0)$ & $0(0)$ & $0(0)$ & $0(0)$ & $0(0)$ \\
\hline$H_{2}^{1}$ & $12(10)$ & $15(10)$ & $14(10)$ & $14(10)$ & $13(10)$ & $13(10)$ & $12(10)$ & $12(10)$ & $11(10)$ & $11(10)$ & $10(10)$ \\
\hline$H_{3}^{1}$ & $0(20)$ & $0(20)$ & $0(20)$ & $6(20)$ & $13(20)$ & $20(20)$ & $25(20)$ & $25(20)$ & $23(20)$ & $22(20)$ & $20(20)$ \\
\hline$H_{4}^{1}$ & $0(0)$ & $0(0)$ & $0(0)$ & $0(0)$ & $0(0)$ & $0(0)$ & $0(0)$ & $0(0)$ & $0(0)$ & $0(0)$ & $0(0)$ \\
\hline$H_{5}^{1}$ & $0(0)$ & $0(0)$ & $0(0)$ & $0(0)$ & $0(0)$ & $0(0)$ & $0(0)$ & $0(0)$ & $0(0)$ & $0(0)$ & $0(0)$ \\
\hline$H_{6}^{1}$ & $0(0)$ & $0(0)$ & $0(0)$ & $0(0)$ & $0(0)$ & $0(0)$ & $0(0)$ & $0(0)$ & $0(0)$ & $0(0)$ & $0(0)$ \\
\hline$H_{1}^{2}$ & $0(0)$ & $0(0)$ & $0(0)$ & $0(0)$ & $0(0)$ & $0(0)$ & $0(0)$ & $0(0)$ & $0(0)$ & $0(0)$ & $0(0)$ \\
\hline$H_{2}^{2}$ & $0(20)$ & $4(20)$ & $8(20)$ & $12(20)$ & $17(20)$ & $20(20)$ & $20(20)$ & $20(20)$ & $20(20)$ & $20(20)$ & $20(20)$ \\
\hline$H_{3}^{2}$ & $0(10)$ & $0(10)$ & $0(10)$ & $0(10)$ & $0(10)$ & $1(10)$ & $10(10)$ & $13(10)$ & $12(10)$ & $11(10)$ & $10(10)$ \\
\hline$H_{4}^{2}$ & $0(0)$ & $0(0)$ & $0(0)$ & $0(0)$ & $0(0)$ & $0(0)$ & $0(0)$ & $0(0)$ & $0(0)$ & $0(0)$ & $0(0)$ \\
\hline$H_{5}^{2}$ & $0(0)$ & $0(0)$ & $0(0)$ & $0(0)$ & $0(0)$ & $0(0)$ & $0(0)$ & $0(0)$ & $0(0)$ & $0(0)$ & $0(0)$ \\
\hline$H_{6}^{2}$ & $0(0)$ & $0(0)$ & $0(0)$ & $0(0)$ & $0(0)$ & $0(0)$ & $0(0)$ & $0(0)$ & $0(0)$ & $0(0)$ & $0(0)$ \\
\hline$L_{1}^{1}$ & $0(10)$ & $1(10)$ & $2(10)$ & $3(10)$ & $4(10)$ & $5(10)$ & $6(10)$ & $7(10)$ & $8(10)$ & $9(10)$ & $10(10)$ \\
\hline$L_{2}^{1}$ & $0(0)$ & $0(0)$ & $0(0)$ & $0(0)$ & $0(0)$ & $0(0)$ & $0(0)$ & $0(0)$ & $0(0)$ & $0(0)$ & $0(0)$ \\
\hline$L_{3}^{1}$ & $0(0)$ & $0(0)$ & $0(0)$ & $0(0)$ & $0(0)$ & $0(0)$ & $0(0)$ & $0(0)$ & $0(0)$ & $0(0)$ & $0(0)$ \\
\hline$L_{4}^{1}$ & $14(0)$ & $11(0)$ & $8(0)$ & $12(0)$ & $16(0)$ & $21(0)$ & $23(0)$ & $20(0)$ & $14(0)$ & $9(1)$ & $4(4)$ \\
\hline$L_{5}^{1}$ & $0(0)$ & $0(0)$ & $0(0)$ & $0(0)$ & $0(0)$ & $0(0)$ & $0(2)$ & $1(5)$ & $3(9)$ & $5(10)$ & $7(7)$ \\
\hline$L_{6}^{1}$ & $4(0)$ & $5(2)$ & $6(5)$ & $7(7)$ & $8(9)$ & $9(11)$ & $10(12)$ & $11(10)$ & $11(9)$ & $11(9)$ & $11(11)$ \\
\hline$L_{1}^{2}$ & $30(50)$ & $32(50)$ & $34(50)$ & $36(50)$ & $38(50)$ & $40(50)$ & $42(50)$ & $44(50)$ & $46(50)$ & $48(50)$ & $50(50)$ \\
\hline$L_{2}^{2}$ & $0(0)$ & $0(0)$ & $0(0)$ & $0(0)$ & $0(0)$ & $0(0)$ & $0(0)$ & $0(0)$ & $0(0)$ & $0(0)$ & $0(0)$ \\
\hline$L_{3}^{2}$ & $0(0)$ & $0(0)$ & $0(0)$ & $0(0)$ & $0(0)$ & $0(0)$ & $0(0)$ & $0(0)$ & $0(0)$ & $0(0)$ & $0(0)$ \\
\hline$L_{4}^{2}$ & $15(0)$ & $15(0)$ & $16(0)$ & $16(0)$ & $17(0)$ & $18(0)$ & $22(0)$ & $22(0)$ & $15(0)$ & $9(0)$ & $3(3)$ \\
\hline$L_{5}^{2}$ & $0(0)$ & $0(0)$ & $0(0)$ & $0(0)$ & $0(1)$ & $0(1)$ & $0(4)$ & $1(7)$ & $5(10)$ & $8(13)$ & 11 (11) \\
\hline$L_{6}^{2}$ & $0(10)$ & $2(11)$ & $3(13)$ & $5(15)$ & $7(16)$ & $8(17)$ & $10(15)$ & $11(14)$ & $11(12)$ & $11(10)$ & $11(11)$ \\
\hline
\end{tabular}

\section{Acknowledgment}

This research was supported by the National Science Council of Taiwan under Contract no. NSC99-2410-H-194-059-MY3.

\section{References}

[1] S. Nam and R. Logendran, "Aggregate production planninga survey of models and methodologies," European Journal of Operational Research, vol. 61, no. 3, pp. 255-272, 1992.

[2] G. Buxey, "A managerial perspective on aggregate planning," International Journal of Production Economics, vol. 41, no. 1-3, pp. 127-133, 1995.

[3] W. J. Stevenson, Operations Management, McGraw-Hill, New York, NY, USA, 7th edition, 2002.

[4] G. Buxey, "Strategy not tactics drives aggregate planning," International Journal of Production Economics, vol. 85, no. 3, pp. 331-346, 2003.
[5] L. J. Krajewski, L. P. Ritzman, and M. K. Malhotra, Operation Management: Processes and Value Chains, Prentice Hall, Upper Saddle River, NJ, USA, 2007.

[6] G. H. Saad, "An overview of production planning model: structure classification and empirical assessment," International Journal of Production Research, vol. 20, no. 1, pp. 105-114, 1982.

[7] C. C. Holt, F. Modigliani, and H. A. Simmon, "A linear decision rule for production and employment scheduling," Management Science, vol. 2, no. 1, pp. 1-30, 1955.

[8] E. H. Bowman, "Production scheduling by the transportation method of linear programming," Operations Research, vol. 4, pp. 100-103, 1956.

[9] A. Charnes and W. W. Cooper, Management Models and Industrial Applications of Linear Programming, John Wiley \& Sons, New York, NY, USA, 1961.

[10] E. H. Bowman, "Consistency and optimality in managerial decision making," Management Science, vol. 9, pp. 310-321, 1963. 
[11] C. Jones, "Parametric production planning," Management Science, vol. 13, pp. 843-866, 1967.

[12] A. Jain and U. S. Palekar, "Aggregate production planning for a continuous reconfigurable manufacturing process," Computers and Operations Research, vol. 32, no. 5, pp. 1213-1236, 2005.

[13] A. Baykasoglu, "MOAPPS 1.0: aggregate production planning using the multiple-objective tabu search," International Journal of Production Research, vol. 39, no. 16, pp. 3685-3702, 2001.

[14] C. Gomes da Silva, J. Figueira, J. Lisboa, and S. Barman, "An interactive decision support system for an aggregate production planning model based on multiple criteria mixed integer linear programming," Omega, vol. 34, no. 2, pp. 167-177, 2006.

[15] S. C. H. Leung, Y. Wu, and K. K. Lai, "A stochastic programming approach for multi-site aggregate production planning," Journal of the Operational Research Society, vol. 57, no. 2, pp. 123-132, 2006.

[16] S. C. H. Leung and S. S. W. Chan, "A goal programming model for aggregate production planning with resource utilization constraint," Computers and Industrial Engineering, vol. 56, no. 3, pp. 1053-1064, 2009.

[17] G. B. Dantzig, "Linear programming under uncertainty," Management Science, vol. 1, pp. 197-206, 1955.

[18] J. Mula, R. Poler, J. P. García-Sabater, and F. C. Lario, "Models for production planning under uncertainty: a review," International Journal of Production Economics, vol. 103, no. 1, pp. 271-285, 2006.

[19] R. Wang and T. Liang, "Application of fuzzy multi-objective linear programming to aggregate production planning," Computers and Industrial Engineering, vol. 46, no. 1, pp. 17-41, 2004.

[20] A. Jamalnia and M. A. Soukhakian, "A hybrid fuzzy goal programming approach with different goal priorities to aggregate production planning," Computers and Industrial Engineering, vol. 56, no. 4, pp. 1474-1486, 2009.

[21] L. A. Zadeh, "Fuzzy sets," Information and Computation, vol. 8, pp. 338-353, 1965.

[22] H. Tanaka, T. Okuda, and K. Asai, "On fuzzy-mathematical programming," Journal of Cybernetics, vol. 3, no. 4, pp. 37-46, 1974.

[23] H. Tanaka, H. Ichihashi, and K. Asai, "A value of information in FLP problems via sensitivity analysis," Fuzzy Sets and Systems, vol. 18, no. 2, pp. 119-129, 1986.

[24] H. Tanaka, "Fuzzy data analysis by possibilistic linear models," Fuzzy Sets and Systems, vol. 24, no. 3, pp. 363-375, 1987.

[25] R. Slowinski and J. Teghem, "Fuzzy versus stochastic approaches to multicriteria linear programming under uncertainty," Naval Research Logistics, vol. 35, no. 6, pp. 673-695, 1988.

[26] H. Zimmermann, Fuzzy Set Theory-and Its Applications, Kluwer Academic, Boston, Mass, USA, 2001.

[27] H. Rommelfanger, "Fuzzy linear programming and applications," European Journal of Operational Research, vol. 92, no. 3, pp. 512-527, 1996.

[28] R. Wang and H. Fang, "Aggregate production planning in a fuzzy environment," International Journal of Industrial Engineering: Theory Applications and Practice, vol. 7, no. 1, pp. 5-14, 2000.

[29] Y. Y. Lee, Fuzzy set theory approach to aggregate production planning and inventory control [Ph.D. thesis], Department of I.E., Kansas State University, 1999.
[30] Y. Lai and C. L. Hwang, Fuzzy Mathematical Programming: Methods and Applications, Springer, Berlin, Germany, 1992.

[31] L. Dai, L. Fun, and L. Sun, "Aggregate production planning utilizing a fuzzy linear programming," Journal of Integrated Design \& Process Science, vol. 7, pp. 81-95, 2003.

[32] R. Wang and H. Fang, "Aggregate production planning with multiple objectives in a fuzzy environment," European Journal of Operational Research, vol. 133, no. 3, pp. 521-536, 2001.

[33] R. Wang and T. Liang, "Applying possibilistic linear programming to aggregate production planning," International Journal of Production Economics, vol. 98, no. 3, pp. 328-341, 2005.

[34] J. Tang, D. Wang, and R. Y. K. Fung, "Fuzzy formulation for multi-product aggregate production planning," Production Planning and Control, vol. 11, no. 7, pp. 670-676, 2000.

[35] T.-F. Liang, "Application of interactive possibilistic linear programming to aggregate production planning with multiple imprecise objectives," Production Planning and Control, vol. 18, no. 7, pp. 548-560, 2007.

[36] R. A. Aliev, B. Fazlollahi, B. G. Guirimov, and R. R. Aliev, "Fuzzy-genetic approach to aggregate production-distribution planning in supply chain management," Information Sciences, vol. 177, no. 20, pp. 4241-4255, 2007.

[37] S. P. Chen and W. L. Huang, "A membership function approach for aggregate production planning problems in fuzzy environments," International Journal of Production Research, vol. 48, no. 23, pp. 7003-7023, 2010.

[38] L. A. Zadeh, "Fuzzy sets as a basis for a theory of possibility," Fuzzy Sets and Systems, vol. 1, no. 1, pp. 3-28, 1978.

[39] R. R. Yager, "A characterization of the extension principle," Fuzzy Sets and Systems, vol. 18, no. 3, pp. 205-217, 1986.

[40] W. F. Bialas and M. H. Karwan, "Two-level linear programming," Management Science, vol. 30, no. 8, pp. 1004-1020, 1984.

[41] M. Sakawa, I. Nishizaki, and Y. Uemura, "Interactive fuzzy programming for two-level linear and linear fractional production and assignment problems: a case study," European Journal of Operational Research, vol. 135, no. 1, pp. 142-157, 2001.

[42] H. A. Taha, Operations Research: An Introduction, Prentice Hall, Upper Saddle River, NJ, USA, 9th edition, 2011.

[43] F. S. Hillier and G. J. Lieberman, Introduction to Operations Research, McGraw-Hill, Singapore, 7th edition, 2001.

[44] M. S. Bazaraa, J. J. Jarvis, and H. D. Sherali, Linear Programming and Network Flows, John Wiley \& Sons, Hoboken, NJ, USA, 3rd edition, 2005.

[45] A. Singhvi and U. V. Shenoy, "Aggregate planning in supply chains by pinch analysis," Chemical Engineering Research and Design, vol. 80, no. 6, pp. 597-605, 2002.

[46] A. S. M. Masud and C. L. Hwang, "An aggregate production planning model and application of three multiple objective decision methods," International Journal of Production Research, vol. 18, no. 6, pp. 741-752, 1980.

[47] A. Kaufmann, Introduction to the Theory of Fuzzy Subsets, Academic Press, New York, NY, USA, 1975.

[48] M. S. Bazaraa, H. D. Sherali, and C. M. Shetty, Nonlinear Programming: Theory and Algorithm, John Wiley \& Sons, 3rd edition, 2006.

[49] LINDO Systems, Lingo User's Guide, LINDO Systems, Chicago, Ill, USA, 1999. 
[50] S. Chanas, "The use of parametric programming in fuzzy linear programming," Fuzzy Sets and Systems, vol. 11, no. 1-3, pp. 229241, 1983.

[51] S. Chanas and M. Kulej, "A fuzzy linear programming problem with equality constraints," Polish Academy of Sciences. Systems Research Institute. Control and Cybernetics, vol. 13, no. 3, pp. 195-201, 1984.

[52] S. H. Chen and S. M. Chang, "Optimization of fuzzy production inventory model with unrepairable defective products," International Journal of Production Economics, vol. 113, no. 2, pp. 887894, 2008. 


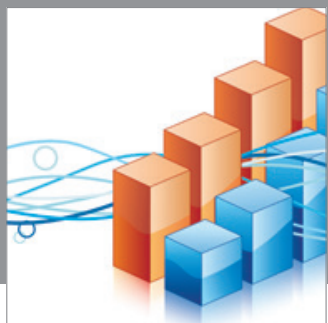

Advances in

Operations Research

mansans

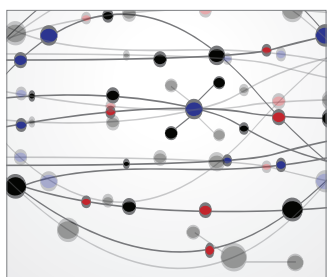

The Scientific World Journal
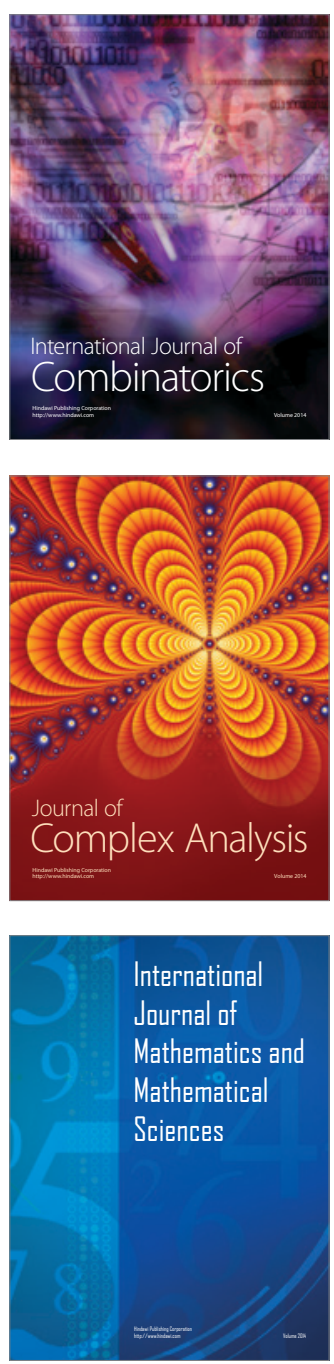
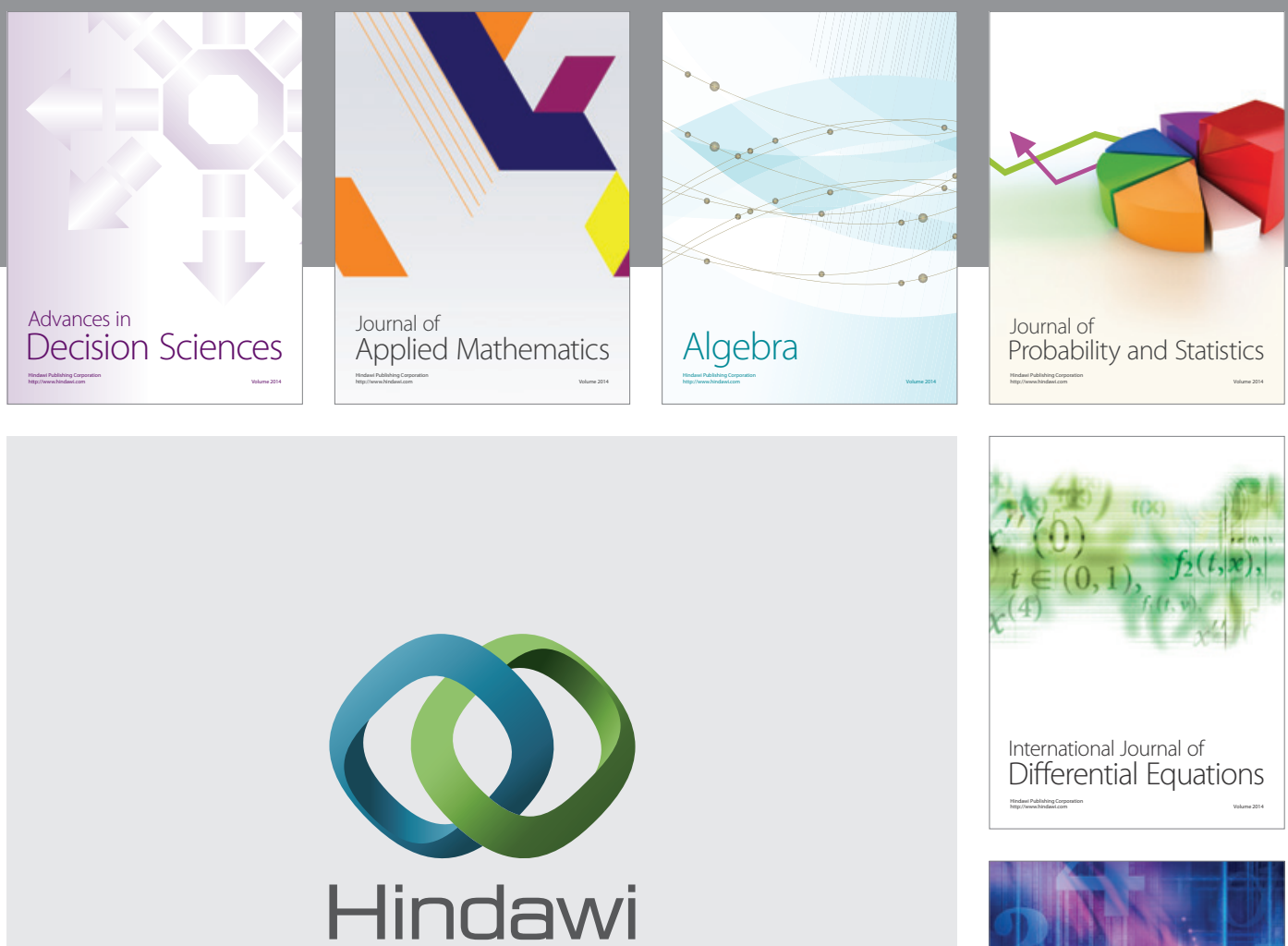

Submit your manuscripts at http://www.hindawi.com
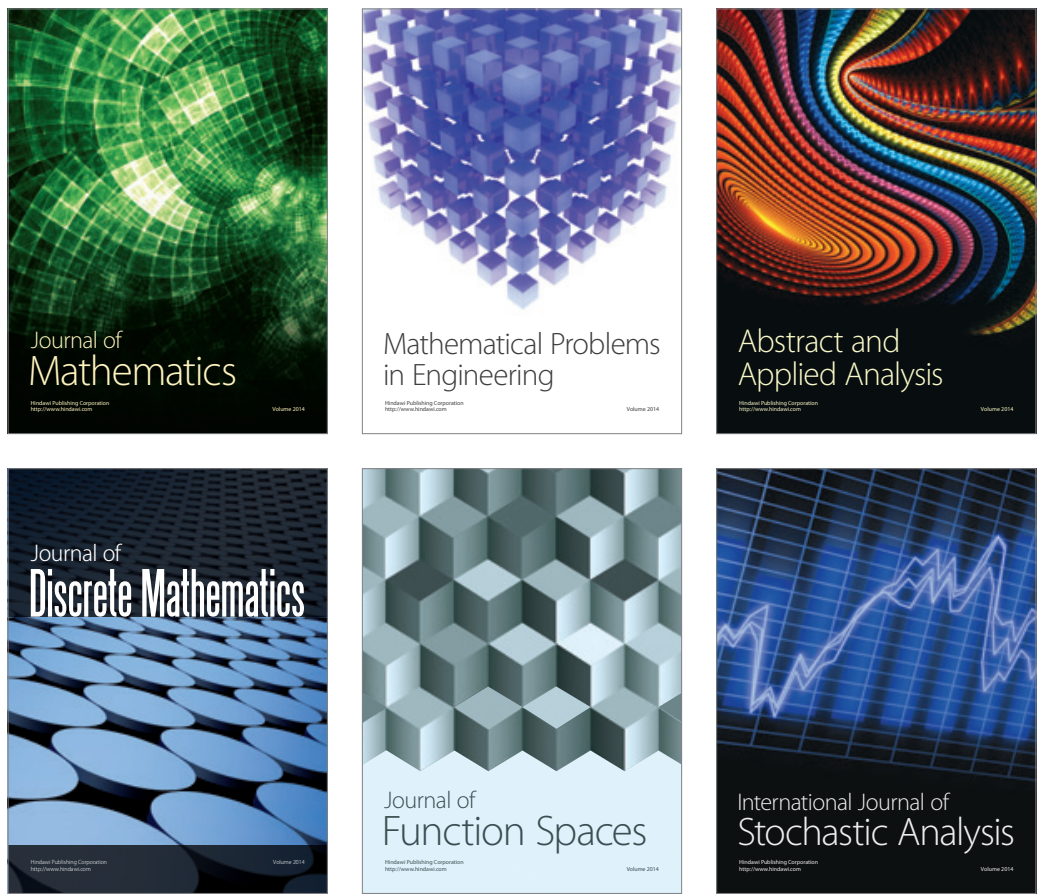

Journal of

Function Spaces

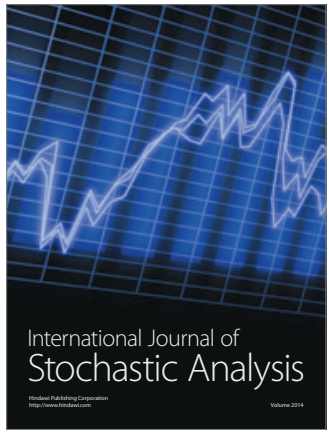

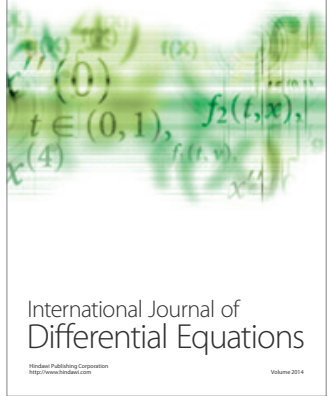
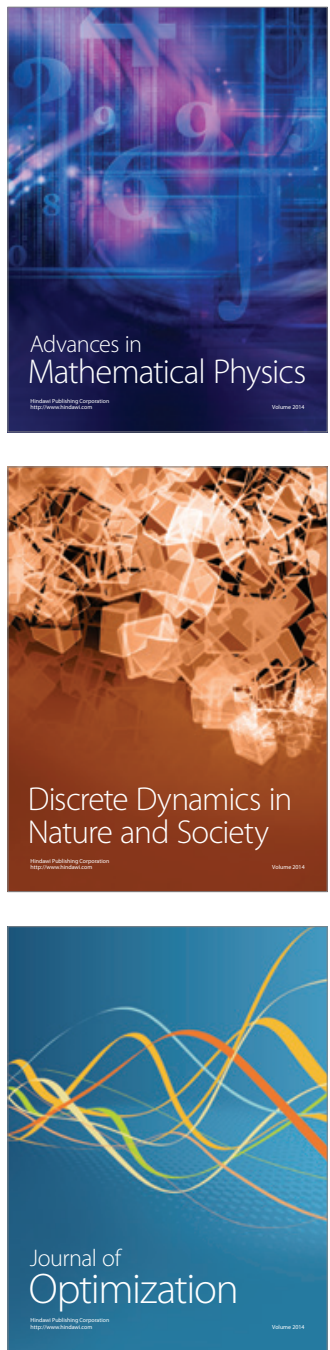